\title{
Carbon Capture From Flue Gas and the Atmosphere: A Perspective
}

\begin{abstract}
Xiaoxing Wang ${ }^{1 *}$ and Chunshan Song ${ }^{1,2,3 *}$
${ }^{1}$ PSU-DUT Joint Center for Energy Research, Clean Fuels and Catalysis Program, EMS Energy Institute and Department of Energy and Mineral Engineering, The Pennsylvania State University, University Park, PA, United States, ${ }^{2}$ Department of Chemical Engineering, The Pennsylvania State University, University Park, PA, United States, ${ }^{3}$ Department of Chemistry, Faculty of Science, The Chinese University of Hong Kong, Hong Kong, China
\end{abstract}

Climate change has become a worldwide concern with the rapid rise of the atmospheric $\mathrm{CO}_{2}$ concentration. To mitigate $\mathrm{CO}_{2}$ emissions, the research and development efforts in $\mathrm{CO}_{2}$ capture and separation both from the stationary sources with high $\mathrm{CO}_{2}$ concentrations (e.g., coal-fired power plant flue gas) and directly from the atmosphere have grown significantly. Much progress has been achieved, especially within the last twenty years. In this perspective, we first briefly review the current status of carbon capture technologies including absorption, adsorption, membrane, biological capture, and cryogenic separation, and compare their advantages and disadvantages. Then, we focus mainly on the recent advances in the absorption, adsorption, and membrane technologies. Even though numerous optimizations in materials and processes have been pursued, implementing a single separation process is still quite energy-intensive or costly. To address the challenges, we provide our perspectives on future directions of $\mathrm{CO}_{2}$ capture research and development, that is, the combination of flue gas recycling and hybrid capture system, and one-step integrated $\mathrm{CO}_{2}$ capture and conversion system, as they have the potential to overcome the technical bottlenecks of single capture technologies, offering significant improvement in energy efficiency and cost-effectiveness.

Keywords: carbon dioxide capture, flue gas, air capture, hybrid system, carbon capture and conversion

\section{INTRODUCTION}

Today's primary energy supply is heavily relying on carbonaceous fuels, mainly the three typical fossil energies, that is, coal, petroleum, and conventional and unconventional natural gas. The control of pollutants emitted from combustion of these fuels in various stationaries including power plants, mobile energy systems, and industrial factories is a major challenge to the environment and human health and safety. It is initially related to the emissions of $\mathrm{SO}_{x}, \mathrm{NO}_{x}$, mercury, and particulate matters. Now, it also involves the emissions of carbon dioxide $\left(\mathrm{CO}_{2}\right)$ and methane $\left(\mathrm{CH}_{4}\right)$, two major greenhouse gases which have been regarded as the main reason for the climate change worldwide. With increasing concerns on global climate change (Melillo et al., 1993; Houghton et al., 2001; IPCC, 2015), reducing greenhouse gases emissions, particularly $\mathrm{CO}_{2}$ emissions, has been significantly heightened in both academia and industry in recent years (Maroto-Valer et al., 2002; Brovkin et al., 2004; Song, 2006), in part because the increased $\mathrm{CO}_{2}$ emissions are believed to contributing to ocean acidification and sea level rise in addition to global warming and climate change.

Since the industrial revolution, $\mathrm{CO}_{2}$ emissions have increased continuously due mainly to the anthropogenic activities. Figure 1 shows the $\mathrm{CO}_{2}$ concentration in the atmosphere within the last six decades from 1958 to 2019. As of December 2019, $\mathrm{CO}_{2}$ concentration in the atmosphere has reached 


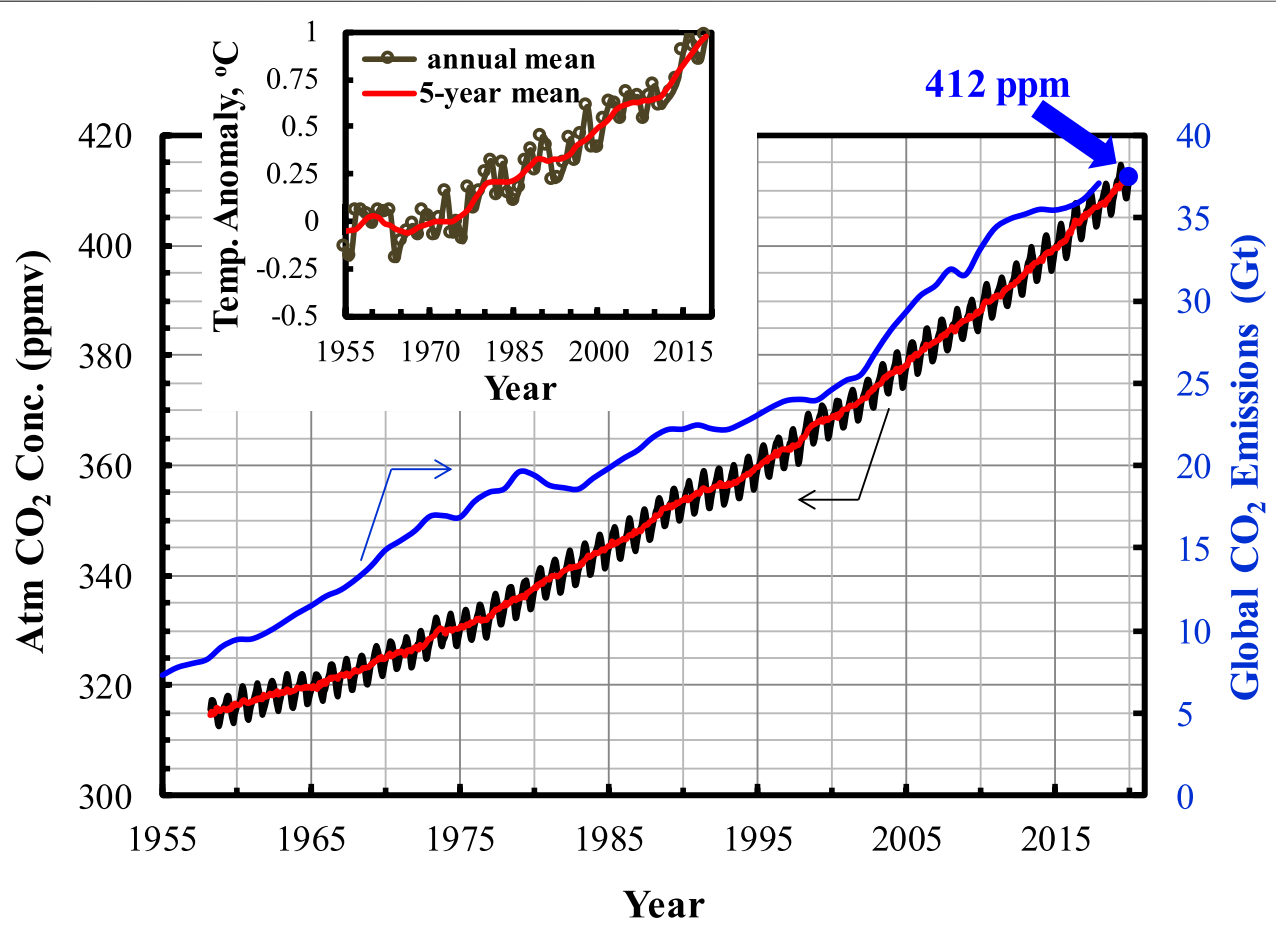

FIGURE 1 | Atmospheric $\mathrm{CO}_{2}$ concentration during 1950-2019 (data sources: http://climate.nasa.gov/vital-signs/carbon-dioxide/).

$412 \mathrm{ppm}$, accounting for about 31\% increase of that in 1958 ( $\sim 5.1 \%$ o per year). In contrast, it took about a hundred years for the atmospheric $\mathrm{CO}_{2}$ concentration to reach $315 \mathrm{ppm}$ by 1958 (IPCC, 2015; Seneviratne et al., 2016), an increase of $\sim 12.5 \%$ $(\sim 1.25 \%$ o per year). Such a change clearly shows that the atmospheric $\mathrm{CO}_{2}$ concentration has increased significantly, and the rising rate becomes faster and faster. The $\mathrm{CO}_{2}$ concentration in air would surpass $550 \mathrm{ppm}$ by 2050 if no action were taken to curb $\mathrm{CO}_{2}$ emissions while keeping fossil fuels utilization as is (Smith and Myers, 2018), possibly reaching to $900-1,100$ ppm by the end of this century (Kiehl, 2011). If so, it could cause catastrophic impact on global climate and human nutrition and societies.

In 2015, a global agreement was reached at the United Nations Climate Change Conference, known as the Paris Agreement. It sets a target of keeping the global temperature rise at $2^{\circ} \mathrm{C}$ or less by the end of the 21st century (United Nations Climate Change, 2015), accentuating well on the urgency in reducing $\mathrm{CO}_{2}$ emissions (Seneviratne et al., 2016). However, with fast growth of global economies and world population which demands more and more energy supply globally, fossil fuels will continue playing a major role. Although the supply of alternative energies such as biomass, solar, and wind is increasing, they are still in the developing stage, yet far from ready to replace the fossil energy completely. Thus, developing strategies to significantly reduce $\mathrm{CO}_{2}$ emissions both from the stationary sources with high $\mathrm{CO}_{2}$ concentrations (e.g., coal-fired power plants, and manufacturing industries) and directly from air have attracted increasing attention worldwide (Lackner, 2003; Song, 2006; Keith,
2009; Lackner et al., 2012; IPCC, 2015; Sanz-Pérez et al., 2016; National Academies of Sciences, Engineering, and Medicine, 2019).

There are several pathways to mitigate $\mathrm{CO}_{2}$ emissions: reducing energy use, improving energy efficiency, shifting to low-carbon or even non-carbon energy, and implementing carbon capture and sequestration (CCS) (Pacala and Socolow, 2004). Reducing energy use is not realistic on a global scale, while improving energy efficiency is a highly challenging task to meet the climate change mitigation goals. The use of low-carbon energy such as natural gas can slow but not be able to solve the problem. Renewable energy such as biomass, wind, and solar is still at its early stage and not able to replace the current fossil fuel-based energy in near future, while the future of nuclear energy is under much debating with big uncertainty. In contrast, carbon capture, utilization, and sequestration (CCUS), which refers to a process that captures $\mathrm{CO}_{2}$ from sources like power plants or ambient air followed by recycling it for utilization or sequestrating it underground permanently, is now widely regarded as a viable option to quickly alleviate $\mathrm{CO}_{2}$ emissions within a midterm. Especially, when the captured $\mathrm{CO}_{2}$ is utilized as a valuable (and renewable) feedstock and cheap carbon source for industrial chemicals and fuels production, it offers a costcompetitive way to solve the contradict between the everincreasing energy demand and $\mathrm{CO}_{2}$ emissions reduction (Markewitz et al., 2012).

Today, the global energy-related $\mathrm{CO}_{2}$ emissions are at the level of 35-37 gigatonnes per year (Gt/yr), with over $80 \%$ coming from fossil fuel combustion--> (National Academies 
of Sciences, Engineering, and Medicine, 2019; IEA, 2010; OECD, 2012). In the United States, the energy-related $\mathrm{CO}_{2}$ emissions are about 5.1-5.3 Gt/yr in recent years (U.S. Energy Information Administration, 2020). Among them, the $\mathrm{CO}_{2}$ emissions from power plants, industrial sector, and the transportation sector account for 30,21, and $26 \%$ of total carbon emissions, respectively (United States Environmental Protection Agency, 2016). Capturing $\mathrm{CO}_{2}$ from these sources is thus critical to maintain or slow down the increase of the atmospheric $\mathrm{CO}_{2}$ level (Sanz-Pérez et al., 2016). About $1.3 \mathrm{Gt}-\mathrm{CO}_{2}$ is emitted annually from the transportation sector in the United States, which is expected to increase significantly by 2050 due to the increasing demand for vehicles and aviation (OECD, 2012). Unfortunately, till today, onboard $\mathrm{CO}_{2}$ capture from the mobile system is still not available. To address the challenge, negative emission strategies have recently been proposed. One method is directly removing $\mathrm{CO}_{2}$ from air, the so-called direct air carbon capture (DACC) (Keith, 2009; Lackner et al., 2012; Sanz-Pérez et al., 2016; National Academies of Sciences, Engineering, and Medicine, 2019). According to the Intergovernmental Panel on Climate Change (IPCC), the current global $\mathrm{CO}_{2}$ emissions are more than those envisaged with the most pessimistic model (Stocker et al., 2013). Thus, combining $\mathrm{CO}_{2}$ capture both from the high and low $\mathrm{CO}_{2}$ concentration sources could be essential to achieve the Paris Agreement goal of limiting anthropogenic global temperature increase below $2^{\circ} \mathrm{C}$.

Aqueous amine scrubbing is the benchmark carbon capture technology currently commercially available in industry (Rochelle, 2009; Rochelle, 2016; Tontiwachwuthikul and Idem, 2013; Darunte et al., 2016). This process, however, is very energy intensive. It is predicted that the required parasitic loads or the socalled energy penalty for $\mathrm{CO}_{2}$ removal is around $0.2-0.5 \mathrm{MWh}$ / ton- $\mathrm{CO}_{2}$, which is equivalent to $20-30 \%$ of power plant output (Rochelle, 2009). Particularly, the absorbent regeneration and $\mathrm{CO}_{2}$ recovery step consumes about $50 \%$ of the overall energy in the form of low-pressure steam for the stripper reboiler due largely to the high heating capacity of water. The high energy penalty induces both high capital cost and operating cost. The use of basic amine solution can cause corrosion to the equipment. Furthermore, the amine loss due to the degradation and evaporation in the process generates pollutants to the environment. It is estimated that the application of the technology could result in the increase in the cost of electricity by $25-40 \%$ (Rubin et al., 2015), thus limiting its widespread use (Haszeldine, 2009). Therefore, developing new technologies to minimize energy penalty and improve cost-effectiveness for carbon capture is highly desired yet quite challenging (Song, 2006; Chu, 2009; Keith, 2009). In this article, we first convey a short review on the R\&D status of carbon capture technologies including absorption, adsorption, membrane, biological capture, and cryogenic separation; compare their advantages and disadvantages; and elaborate mainly on absorption, adsorption, and membrane technologies more in detail. Then, we provide our perspective on future directions in $\mathrm{CO}_{2}$ capture research and development.

\section{CURRENT STATUS OF CARBON CAPTURE TECHNOLOGIES}

Currently, several technological pathways are pursued for $\mathrm{CO}_{2}$ separation and capture including carbon capture from postcombustion, pre-combustion, oxy-combustion, chemical looping combustion (CLC), and ambient air as well, which is illustrated in Figure 2. Table $\mathbf{1}$ lists the advantages and disadvantages of those pathways (Figueroa et al., 2008; Rackley, 2017).

- Post-combustion capture involves $\mathrm{CO}_{2}$ separation from flue gases after combustion, which has a low $\mathrm{CO}_{2}$ partial pressure (0.03-0.2 bar) and/or a low $\mathrm{CO}_{2}$ concentration (3-20\%) (Figueroa et al., 2008; Feron and Hendriks, 2005). The carbon capture from some industrial sources such as cement manufacturing, stainless steel factory can also be categorized into post-combustion capture, although the $\mathrm{CO}_{2}$ concentration from those industrial processes is higher than that of a typical flue gas from post-combustion power plants. Table 2 lists the typical $\mathrm{CO}_{2}$ concentration of a flue gas stream from various sources (Metz et al., 2005; Husebye et al., 2012; Liguori and Wilcox, 2018). The commercially available post-combustion capture process is the chemical absorption-based aqueous amine solution, such as $30 \%$ monoethanolamine (MEA) solution. Postcombustion capture is considered as a more viable option for existing coal-fired power plants (Wang Y. et al., 2017).

- In a pre-combustion process, which is based on the scaled industrial processes for the production of hydrogen and chemical commodities (Jansen et al., 2015), fuel feedstocks (i.e., coal and natural gas) are converted into syngas $\left(\mathrm{H}_{2}\right.$ and CO) via gasification, steam reforming, auto thermal reforming, or partial oxidation (Steinberg and Cheng, 1989), and then $\mathrm{CO}$ is transferred into $\mathrm{CO}_{2}$ by water, with more hydrogen produced (the so-called water-gas shift reaction, WGS), followed by carbon capture system to remove $\mathrm{CO}_{2}$. After $\mathrm{CO}_{2}$ is captured, the hydrogen-rich fuel gas is utilized for power and heat generation such as boilers, gas turbines, and fuel cells (Metz et al., 2005). After WGS, the $\mathrm{CO}_{2}$ concentration in the flue gas is relatively high, which is in the range of $15-60 \%$ (dry basis) at a total pressure of 2-7 MPa (Gazzani et al., 2013a; Gazzani et al., 2013b), thus physical solvents such as Selexol and Rectisol rather than chemical solvents are commonly used for precombustion capture.

- Oxy-combustion is a relatively new technology (Jurado et al., 2015) and involves the combustion of fuel feedstocks in a nearly pure oxygen (95-99\%) or $\mathrm{O}_{2}-\mathrm{CO}_{2}$-rich environment (Miller, 2017), resulting in a flue gas with very high $\mathrm{CO}_{2}$ concentration, where the capture of $\mathrm{CO}_{2}$ is thus normally not needed and $\mathrm{CO}_{2}$ is basically ready for sequestration (Miller, 2017; Li et al., 2018; Wu et al., 2019). However, in order to obtain nearly pure oxygen (>95\%) (Kather et al., 2008), usually a cryogenic air separation unit is required for oxygen separation from air, which makes the whole process costly. 


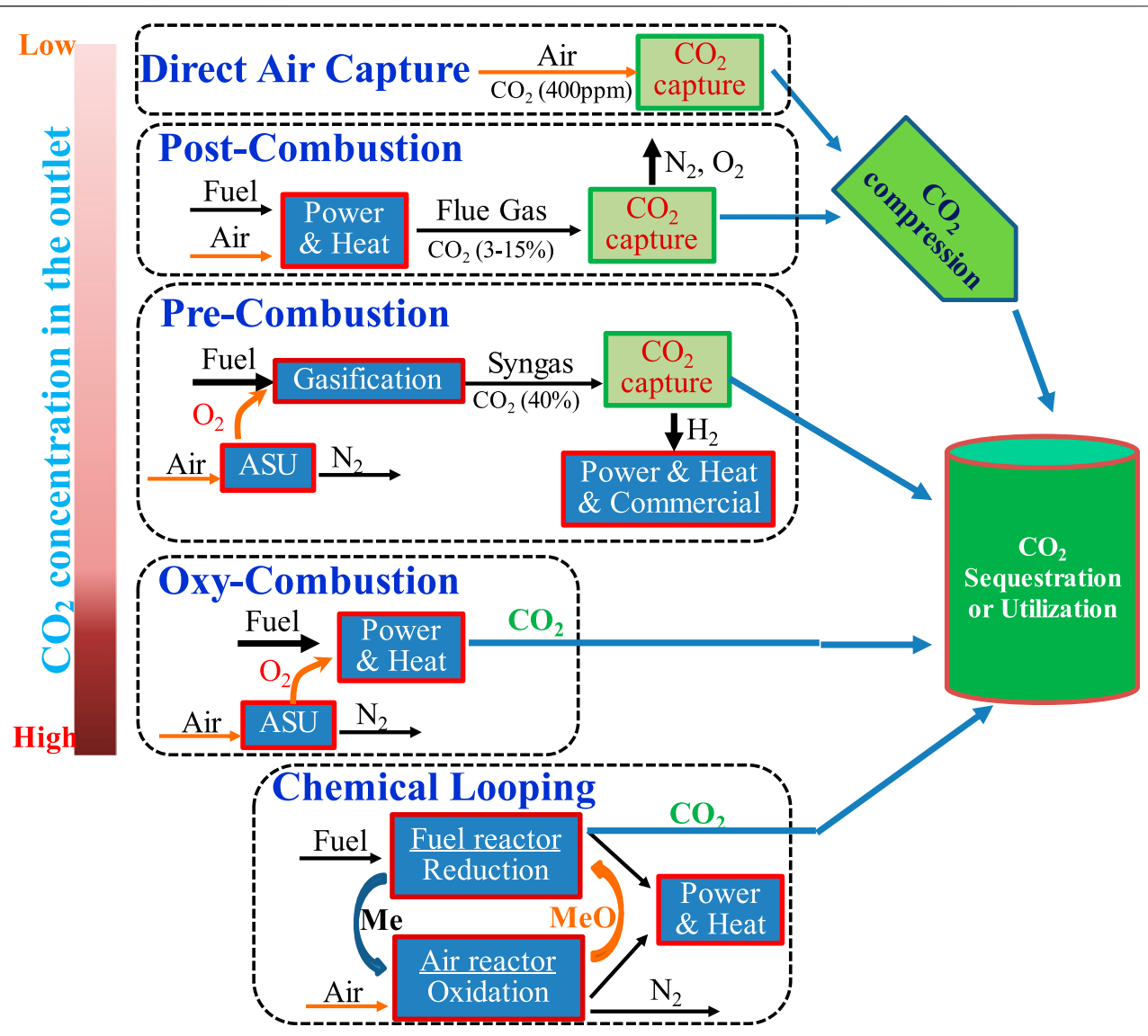

FIGURE 2 | Schematic diagram of the existing $\mathrm{CO}_{2}$ capture pathways.

- CLC is an emerging combustion process similar to oxycombustion producing the $\mathrm{CO}_{2}$-concentrated flue gas (Abanades et al., 2015; Miller, 2017), so that the separation of $\mathrm{CO}_{2}$ from fuel gas (e.g., pre-combustion) or flue gas (e.g., post-combustion) is not needed. In a typical chemical looping process, an oxygen carrier such as $\mathrm{Fe}, \mathrm{Mn}$, $\mathrm{Cu}, \mathrm{Ni}$, and Co metals is oxidized in air in one reactor (called the air-reactor), which is then reduced with a hydrocarbon fuel in another reactor (called the fuel-reactor) to regenerate the metal and release $\mathrm{CO}_{2}$ and water (Abanades et al., 2015). The metal is then sent back to start another cycle in the airand fuel-reactors. The exothermic air-reactor provides higher temperature heat and power, while the fuelreactor can also generate some heat and power as well. CLC was introduced first by Lewis et al. (Lewis et al., 1951) and later applied for $\mathrm{CO}_{2}$ mitigation by Ishida et al. (Ishida et al., 1987; Ishida and Jin, 1994). Since then over 900 materials have been tested (Lyngfelt and Mattisson, 2011) and number of reviews have been published (Fan, 2010; Adanez et al., 2012; Lyngfelt, 2014; Abanades et al., 2015). Compared to oxy-combustion, CLC eliminates the costly air separation unit, thus is more cost-effective, but the process is relatively more complicated, requiring more studies. To be more cost competitive, a suitable metal/metal-oxide pair as the oxygen carrier plays a critical role in the chemical looping process. More recently, the machine learning algorithms and artificial neural networks have been utilized to estimate the performance of hetero- and multi-component materials as oxygen carriers for CLC (Yan et al., 2020).

- DACC represents a process for $\mathrm{CO}_{2}$ extraction or removal directly from the atmosphere, which was first introduced for the mitigation of climate change by Lackner in 1999 (Lackner et al., 1999). DACC could play a crucial role for $\mathrm{CO}_{2}$ capture from decentralized and mobile emission sources such as vehicles, ships, or air planes (Sanz-Pérez et al., 2016; Bhown et al., 2020; Jones, 2011; Goeppert et al., 2012), thus gaining increasing attention. In 2012, Kulkarni and Sholl (Kulkarni and Sholl, 2012) developed a steambased process using aminosilica sorbents, which can recover $\mathrm{CO}_{2}$ at 1-3 ton/unit/year. Currently, multiple companies including Carbon Engineering (Carbon Engineering, 2020), Climeworks (Climeworks, 2020), and Global Thermostat (Global Thermostat, 2020) are developing DACC systems at a commercial scale. However, it is quite challenging due to the exceptionally low $\mathrm{CO}_{2}$ concentration ( $\sim 400 \mathrm{ppm}$ in air). It requires moving very large volume of air through the capture unit and high adsorption heat to execute the $\mathrm{CO}_{2}$ 


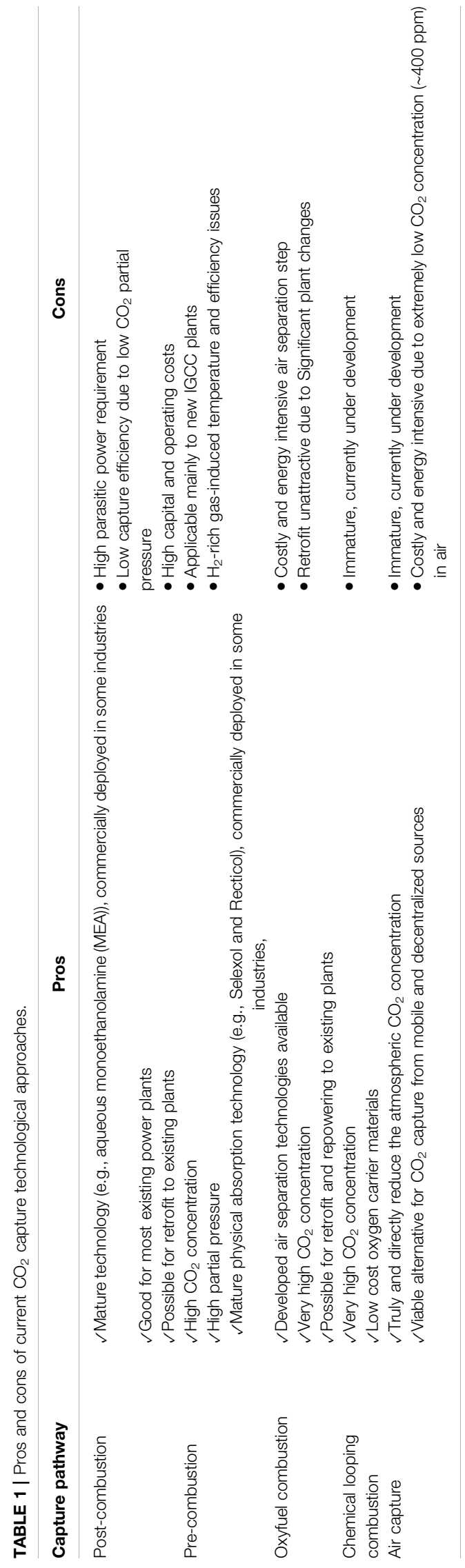

extraction, making this pathway more energy intensive and costly than removing $\mathrm{CO}_{2}$ from the concentrated sources. There is a debate on whether DACC is an enabling factor (Realmonte et al., 2019; Azarabadi and Lackner, 2020) or just a costly distraction for effective climate change mitigation (Chatterjee and Huang, 2020).

Other industrial processes such as hydrogen production, ammonia synthesis, and methanol manufacture release the tail gases with a high concentration of $\mathrm{CO}_{2}$, which could be captured and directly used or transported for storage after some purification. Similar to the oxy-combustion and CLC processes, an individual $\mathrm{CO}_{2}$ capture unit is normally not needed for those processes.

As shown in Figure 2, only post-combustion capture, precombustion capture and air capture require a $\mathrm{CO}_{2}$ capture system. So far, many technological approaches are available for a carbon capture system; however, the choice of a specific capture technology differs widely depending on the sources and $\mathrm{CO}_{2}$ generating processes, resulting in different energy penalties. Figure 3 illustrates various $\mathrm{CO}_{2}$ capture technologies including absorption, adsorption, membrane, biological capture, and cryogenic capture under investigation in both academia and industry for the past few decades, while Table 3 briefly compares the advantages and limitations of these carbon capture technologies (Singh and Dhar, 2019). Among them, absorption, adsorption, and membrane methods are more intensively studied, thus are further discussed in the following section.

\section{Absorption}

Among the abovementioned $\mathrm{CO}_{2}$ capture options, the technology based on liquid absorption is most mature and commercially available, especially in the petroleum and chemical industries. Based on the nature of the interaction between the absorbent and $\mathrm{CO}_{2}$, it separates as chemical absorption (mainly applied for $\mathrm{CO}_{2}$ capture from post-combustion flue gas) and physical absorption (mainly used for $\mathrm{CO}_{2}$ capture from pre-combustion flue gas). Aqueous amine solutions (e.g., 20-30 wt\% MEA, and diethanolamine (DEA)) and liquid ammonia are typical solvents for chemical absorption. MEA solution has become the benchmark amine for $\mathrm{CO}_{2}$ capture from power plants because it has good $\mathrm{CO}_{2}$ transfer rates, relatively low cost, and biodegradable. However, it suffers from toxicity and solvent loss due to evaporation and degradation (Bui et al., 2018). In addition, at higher concentrations, MEA solution is highly corrosive to the equipment.

Developing new $\mathrm{CO}_{2}$ absorbents to replace MEA has thus aroused much interests and is still ongoing. Normally, thermal swing absorption-regeneration is used for chemical absorption; thus, selecting an absorbent with optimized thermal and physical properties is crucial to the development of energy-efficient and cost-effective carbon capture absorption technology. So far, a large number of solvents, including single amines, amine blends, and amino acids, have been evaluated individually for their performance in $\mathrm{CO}_{2}$ capture (Bui et al., 2018; Sreedhar et al., 2017). Figure 4 shows the $\mathrm{CO}_{2}$ absorption capacities in mol- $\mathrm{CO}_{2}$ 
TABLE 2 | Typical $\mathrm{CO}_{2}$ concentration of a flue gas from various sources (Metz et al., 2005; Husebye et al., 2012; Liguori and Wilcox, 2018).

Flue gas source

$\mathrm{CO}_{2}$ conc. (\%)

P (atm)

$\mathrm{CO}_{2}$ partial pressure (atm)

Gas turbine

Fired boiler of oil refinery and petrochemical plant

3-4

$\sim 8$

$7-10$

$11-13$

$12-14$

12-14

15-20

20-27

1-2

14-33
0.03-0.04

0.08

$0.07-0.10$

$0.11-0.13$

$0.12-0.14$

$0.12-0.14$

3-5

$0.2-06$

$0.01-0.02$

$0.14-0.33$

Cement process

a/GCC, integrated gasification combined cycle. Data extracted from the literature (Figueroa et al., 2008; Chu, 2009).

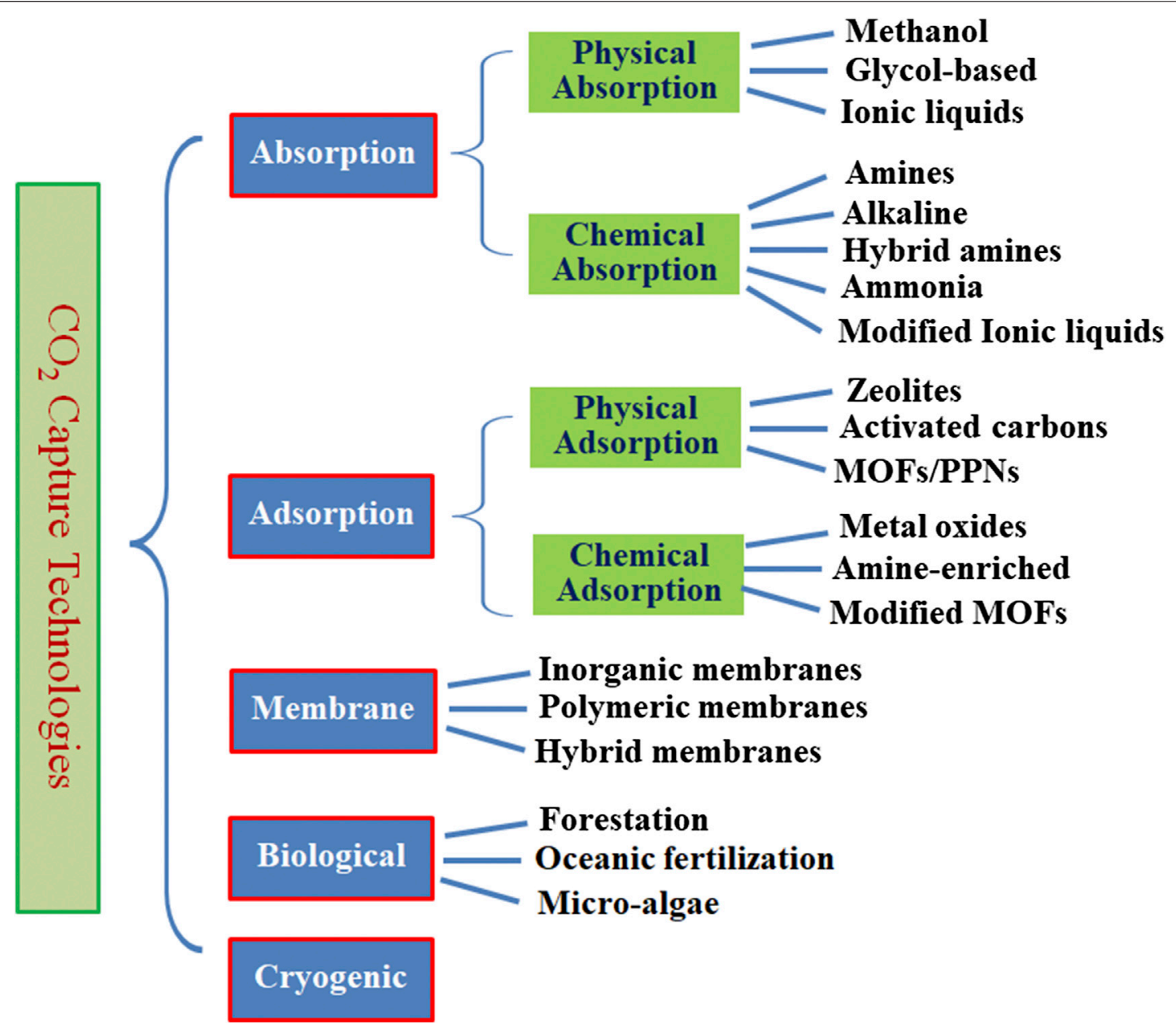

FIGURE 3 | Illustration of various $\mathrm{CO}_{2}$ capture technologies along with typical materials currently under investigation.

per mol-amine obtained at $40^{\circ} \mathrm{C}$ and $\mathrm{CO}_{2}$ partial pressure of $15 \mathrm{kPa}$ using different amines with different structures at different amine concentrations (Shen and Li, 1992; Jou et al., 1995; Park et al., 2002; Benamor and Aroua, 2005; Derks et al., 2005; Maneeintr et al., 2009; Puxty et al., 2009; Chen and
Rochelle, 2011; Rebolledo-Morales et al., 2011; Schäffer et al., 2012; Tong et al., 2012; Chang et al., 2013; Monteiro et al., 2013; Yamada et al., 2013; Arshad et al., 2014; Bougie and Iliuta, 2014; Li et al., 2014; Li and Rochelle, 2014; Nouacer et al., 2014; Chen S. et al., 2015; Conway et al., 2015; Mondal et al., 2015; El Hadri 
TABLE 3 | Comparison of typical $\mathrm{CO}_{2}$ capture technologies.

\begin{tabular}{|c|c|c|c|c|}
\hline \multicolumn{2}{|l|}{ Technology } & \multirow[t]{2}{*}{ Mechanisms } & Pros & Cons \\
\hline Absorption & $\begin{array}{l}\text { Chemical absorption (e.g., MEA and } \\
\qquad \mathrm{NaOH})\end{array}$ & & $\begin{array}{l}\checkmark \text { High capacity at low } \mathrm{CO}_{2} \text { pressure } \\
\checkmark \text { Mature technology }\end{array}$ & $\begin{array}{l}\text { - Energy-intensive regeneration } \\
\text { - Low absorption-desorption rate } \\
\text { - Corrosion } \\
\text { - Absorbent degradation } \\
\text { - High operating cost }\end{array}$ \\
\hline & $\begin{array}{l}\text { Physical absorption (e.g.,methanol, } \\
\text { Selexol, and Rectisol) }\end{array}$ & The solubility of $\mathrm{CO}_{2}$ in a solvent & $\begin{array}{l}\checkmark \text { High capacity at low temperature and } \\
\text { high pressure } \\
\sqrt{ } \text { Cheaper solvent } \\
\checkmark \text { Mature technology }\end{array}$ & $\begin{array}{l}\text { - Low selectivity } \\
\text { - High energy consumption } \\
\text { - Low capacity at high temperature and low pressure } \\
\text { - Absorbent loss }\end{array}$ \\
\hline \multirow[t]{4}{*}{ Adsorption } & $\begin{array}{l}\text { Physical adsorbents (e.g., AC, } \\
\text { zeolites, and MOF) }\end{array}$ & $\begin{array}{l}\text { Molecular sieve confinement effect of solid } \\
\text { materials, normally with micropores }\end{array}$ & $\begin{array}{l}\checkmark \text { High capacity at low temperature and } \\
\text { high pressure } \\
\checkmark \text { Low waste generation }\end{array}$ & $\begin{array}{l}\text { - Low } \mathrm{CO}_{2} \text { selectivity } \\
\text { - Capacity decreases with temperature } \\
\text { - Normally require high pressure } \\
\text { - Moisture degrades the adsorbent performance }\end{array}$ \\
\hline & $\begin{array}{l}\text { Chemical adsorbents (e.g., } \mathrm{CaO} \text { and } \\
\left.\qquad \mathrm{Na}_{2} \mathrm{SiO}_{3}\right)\end{array}$ & $\begin{array}{l}\text { Through the formation of carbonates or } \\
\text { bicarbonates }\end{array}$ & $\begin{array}{l}\checkmark \text { Work at high temperature } \\
\checkmark \text { High capacity }\end{array}$ & - Require high temperature for $\mathrm{CO}_{2}$ sorption and adsorbent regeneration \\
\hline & - & - & $\checkmark$ Low waste generation & $\begin{array}{l}\text { - High energy consumption } \\
\text { - Performance loss with cycles }\end{array}$ \\
\hline & Solid amine sorbents (e.g., $\mathrm{PEI} / \mathrm{SiO}_{2}$ ) & $\begin{array}{l}\text { Chemical reaction between amine groups and } \\
\mathrm{CO}_{2}\end{array}$ & $\begin{array}{l}\checkmark \text { High capacity at low } \mathrm{CO}_{2} \text { pressure } \\
\checkmark \text { High selectivity } \\
\sqrt{ } \text { Fast kinetics } \\
\sqrt{ } \text { Mild conditions } \\
\checkmark \text { Positive effect of moisture } \\
\checkmark \text { Lower energy consumption } \\
\sqrt{ } \text { Less corrosion } \\
\sqrt{ } \text { Low waste generation }\end{array}$ & $\begin{array}{l}\text { - Thermal and oxidative degradation } \\
\text { - Degradation due to contaminants (e.g., } \mathrm{SO}_{x} \text { and } \mathrm{NO}_{x} \text { ) }\end{array}$ \\
\hline Membrane & & Different gas permeability & $\begin{array}{l}\checkmark \text { Relatively low operation cost } \\
\checkmark \text { Easy handling and Operation }\end{array}$ & $\begin{array}{l}\text { - High manufacturing cost } \\
\text { - Relatively low separation selectivity } \\
\text { - Permeability still low } \\
\text { - Negative effect of moisture }\end{array}$ \\
\hline \multirow{2}{*}{\multicolumn{2}{|c|}{ Biological absorption/utilization }} & $\begin{array}{l}\text { Captured and utilized through photosynthesis in } \\
\text { plants }\end{array}$ & $\checkmark$ No hazards of chemicals & $\begin{array}{l}\text { - Long time requirement } \\
\text { - Large area requirement } \\
\text { - May affect biological diversity }\end{array}$ \\
\hline & & & $\begin{array}{l}\checkmark \text { Coproduction of food, biofuels, and } \\
\text { value-added products }\end{array}$ & $\begin{array}{l}\text { - Sensitive to other flue gas contaminants (e.g., } \mathrm{SO}_{x} \text { and } \mathrm{NO}_{x} \text { ) and culture } \\
\text { conditions ( } \mathrm{pH} \text {, temperature, and salinity) }\end{array}$ \\
\hline \multicolumn{2}{|c|}{ Cryogenic separation } & Different condensation temperature & $\checkmark$ High capture efficiency (up to $99.9 \%$ ) & $\begin{array}{l}\text { - High energy requirement } \\
\text { - Low efficiency } \\
\text { - Moisture pre-removal is required } \\
\text { - Solidified } \mathrm{CO}_{2} \text { may be accumulated on the surface of heat exchanger }\end{array}$ \\
\hline
\end{tabular}




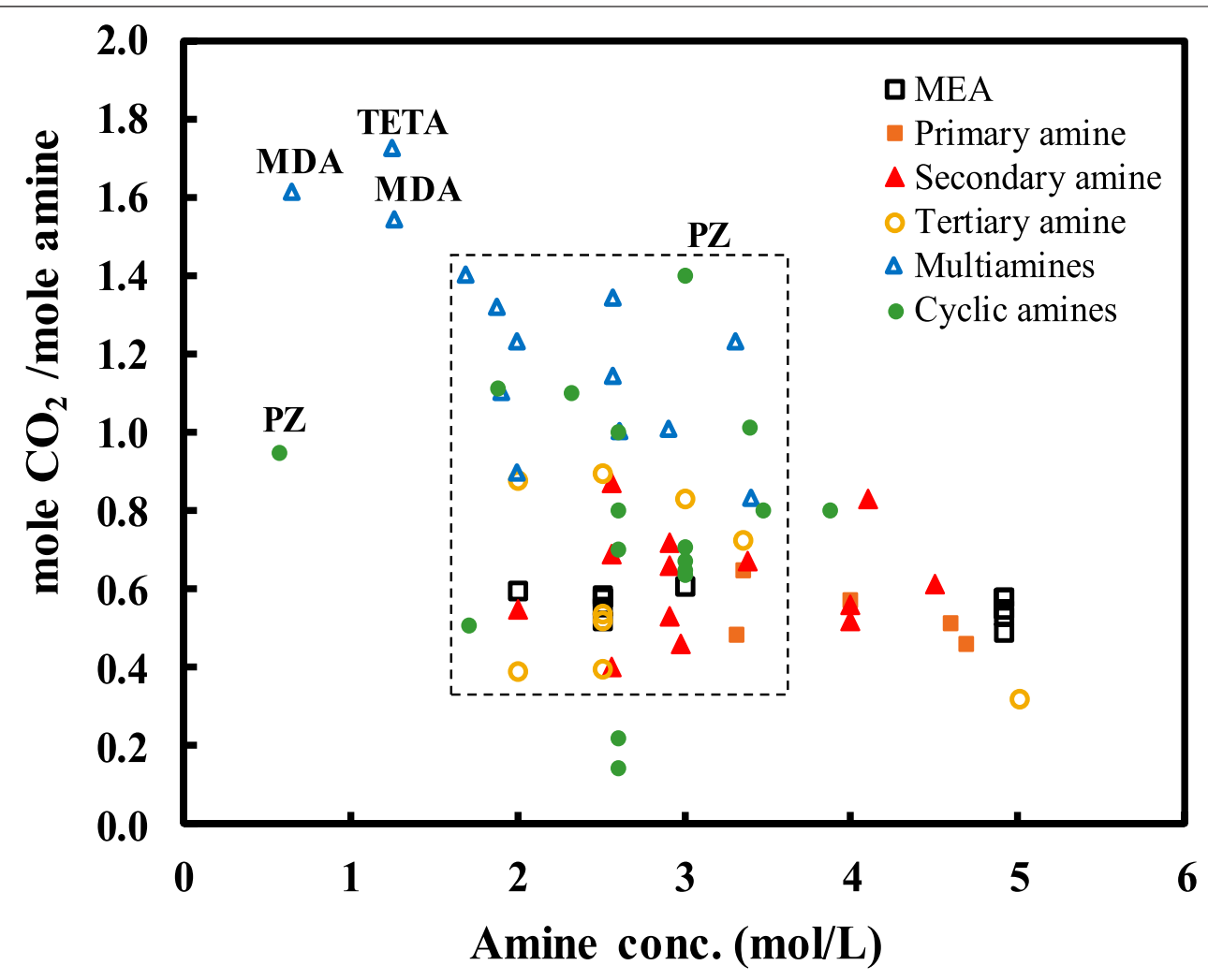

FIGURE 4 | $\mathrm{CO}_{2}$ uptakes obtained at $40^{\circ} \mathrm{C}$ and $\mathrm{CO}_{2}$ partial pressure of $15 \mathrm{kPa}$ using different liquid amines with different structures at different amine concentrations. Data from the literature (Shen and Li, 1992; Jou et al., 1995; Park et al., 2002; Benamor and Aroua, 2005; Derks et al., 2005; Maneeintr et al., 2009; Puxty et al., 2009; Chen and Rochelle, 2011; Rebolledo-Morales et al., 2011; Schäffer et al., 2012; Tong et al., 2012; Chang et al., 2013; Monteiro et al., 2013; Yamada et al., 2013; Arshad et al., 2014; Bougie and lliuta, 2014; Li et al., 2014; Li and Rochelle, 2014; Nouacer et al., 2014; Chen S. et al., 2015; Conway et al., 2015; Mondal et al., 2015; El Hadri et al., 2017).

et al., 2017). The majority were examined at the amine concentration between 2 and $3.5 \mathrm{~mol} / \mathrm{L}$. The $\mathrm{CO}_{2}$ absorption capacity is ranged from 0.4 to $1.4 \mathrm{~mol}-\mathrm{CO}_{2} / \mathrm{mol}$-amine. More specifically, for the primary, secondary, and tertiary mines in straight chains, multi-amines, and amines in cyclic chains, their capacities are in the range of $0.5-0.7,0.4-0.8,0.4-0.9,0.8-1.4$, and $0.5-1.1 \mathrm{~mol}-\mathrm{CO}_{2} / \mathrm{mol}$-amine, respectively. The $\mathrm{CO}_{2}$ absorption capacity decreases generally following the amine structure as cyclic amines $\approx$ multi-amines $>$ tertiary-amines $>$ secondary-amines $>$ primary-amines. Among them, piperazine (PZ) absorbent has been suggested as a good alternative to conventional chemical solvents. Compared to MEA, it shows fast kinetics in reaction with $\mathrm{CO}_{2}$, better chemical stability, and requires lower energy input for regeneration (Rochelle, 2009; Dugas and Rochelle, 2011). It also exhibits better resistance to oxidative and thermal degradation (Freeman et al., 2010a). Other amine blends such as PZ/AMP (Seo and Hong, 2000; Khan et al., 2016) and $\mathrm{K}_{2} \mathrm{CO}_{3} / \mathrm{PZ}$ (Tim Cullinane et al., 2005; Cullinane and Rochelle, 2006) have also been studied, and it has been found that the blending can improve the absorption kinetics, thermodynamic efficiency, and resistance to degradation. The main drawback of $\mathrm{PZ}$ is that it could form precipitation and nitrosamine during $\mathrm{CO}_{2}$ capture process (Freeman et al., 2010b; Cousins et al., 2015).
There is another class of amine-based solvents which is called phase-change solvents including amine-alcohol system and amine-water system. Upon $\mathrm{CO}_{2}$ absorption or increasing the temperature after $\mathrm{CO}_{2}$ absorption, the solvent divides into two phases: $\mathrm{CO}_{2}$-rich and $\mathrm{CO}_{2}$-lean phases (Zhuang et al., 2016; Papadopoulos et al., 2019). In contrast to traditional solvents, only the $\mathrm{CO}_{2}$-rich phase is sent for regeneration; therefore, the energy demand and the size of the regenerator can be dramatically reduced in comparison to non-phase-change solvents. Gomez et al. compared the performance of phasechange solvent process to the conventional MEA process, showing the $\mathrm{CO}_{2}$ capture cost could be saved by $15.4 \%$ for the power plant, and as much as $51.7 \%$ for the cement plant (Gomez et al., 2014). Although the phase-change absorbent systems exhibit some potential merits and economic incentives for scaling up, they may be volatile and corrosive due to the use of amine solution in nature. The formation of precipitation and salts is another important issue for the implementation of the phase-change solvent-based absorption process.

Besides the chemisorption using amine solutions, another type of absorption technology is using physical solvents to absorb $\mathrm{CO}_{2}$, which is based on their $\mathrm{CO}_{2}$ solubility (Chakma, 1999). Physical absorption is generally preferred at higher pressures. Selexol, Rectisol, Purisol, and Fluor are the well-established commercial 
physical absorption technologies, and also energy-intensive processes due to their heat transfer requirements (Figueroa et al., 2008). Since the physical absorption is depended on physical interaction rather than chemical reaction, it normally requires higher partial pressure of $\mathrm{CO}_{2}$ and is preferred at low temperatures in order to achieve high $\mathrm{CO}_{2}$ capture capacity, which thus reduces its efficiency and increases its operation cost.

Recently, ionic liquids (ILs), which consist of ions and act as liquid at room temperature (Hallett and Welton, 2011), are considered as suitable alternatives to the traditional physical absorbents, because ILs have unique properties such as low volatility, low vapor pressure, and good thermal stability (Bates et al., 2002; Corvo et al., 2015; Zeng et al., 2017). In addition, after $\mathrm{CO}_{2}$ absorption, its energy requirement for regeneration is also relatively low. Figure 5 presents the $\mathrm{CO}_{2}$ absorption capacities of some typical ILs (Zhang et al., 2008; PérezSalado Kamps et al., 2003; Shiflett and Yokozeki, 2005; Shin et al., 2008; Carvalho et al., 2010; Kilaru and Scovazzo, 2008; Anderson et al., 2007; Aki et al., 2004; Blanchard et al., 2001). As seen, the $\mathrm{CO}_{2}$ absorption capacity varies with the type of ionic liquid. The highest value of $0.88 \mathrm{~mol}-\mathrm{CO}_{2} / \mathrm{mol}-\mathrm{IL}$ (moles of $\mathrm{CO}_{2}$ per mole of IL) was obtained with [THTDP][NTf2] ionic liquid, while the $[\mathrm{hmpy}][\mathrm{Tf} 2 \mathrm{~N}]$ ionic liquid gave the lowest value of $0.20 \mathrm{~mol}-\mathrm{CO}_{2} / \mathrm{mol}-\mathrm{IL}$ (Anderson et al., 2007). The max $\mathrm{CO}_{2}$ solubility in ILs reported in the literature is largely within the range of $0.4-0.8 \mathrm{~mol}-\mathrm{CO}_{2} / \mathrm{mol}-\mathrm{IL}$, which is comparable to those of most aqueous amine solutions as shown in Figure 4. However, their high viscosities and relatively low working capacity are the two main obstacles for their application in $\mathrm{CO}_{2}$ capture. To attain higher $\mathrm{CO}_{2}$ capacity, a series of the so-called task-specific ILs have been designed by incorporation of various functionalities, such as carboxylate anions, amine and amino acid groups, or azolates for chemisorption of $\mathrm{CO}_{2}$, thereby significantly boosting the absorption capacity up to about 0.5-2.0 mol- $\mathrm{CO}_{2} / \mathrm{mol}-\mathrm{IL}$ under atmospheric pressure (Bates et al., 2002; Giernoth, 2010; Wappel et al., 2010; Petkovic et al., 2011; Shannon and Bara, 2012; Cui et al., 2016). Several groups have also studied the physical and chemical properties of $\mathrm{CO}_{2}$-IL systems using thermodynamic modeling (Zhang et al., 2008; de Riva et al., 2017), kinetics (Wang C. et al., 2011; Moya et al., 2014; de Riva et al., 2017) and $\mathrm{CO}_{2}$ sorption mechanisms (Carvalho et al., 2009; Shiflett et al., 2010). Although higher capacity can be obtained, the functionalized ILs show higher viscosities than unfunctionalized ILs. Therefore, how to greatly reduce the viscosity while maintaining its high capacity is the largest technical challenge for the successful use of ILs in CCS. High cost and difficulty in scale-up are other two significant barriers to the wide spread of ILs for CCS (Singh and Dhar, 2019).

\section{Adsorption}

Adsorption is widely deemed as a promising technology for $\mathrm{CO}_{2}$ capture as it can be retrofitted to any power plants, operated at various conditions with relatively high capacity, high $\mathrm{CO}_{2}$ selectivity, and low energy requirement for regeneration. It can be applied for both pre- and post-combustion pathways (Bui et al., 2018). If waste materials are utilized for preparation of adsorbents, the adsorption process could be potentially more sustainable. It should also be highlighted that adsorption method is well suited for $\mathrm{CO}_{2}$ capture directly from air.

Currently, most efforts in developing advanced adsorbents have been focused on improving $\mathrm{CO}_{2}$ adsorption capacity, $\mathrm{CO}_{2}$ selectivity, and impurity tolerance. So far, a large number of solid adsorbents have been investigated, including carbons and carbon nanotubes (Aaron and Tsouris, 2005; Huang et al., 2007; Plaza et al., 2007; Razavi et al., 2011), clays and oxides (Ding and Alpay, 2000; Yong et al., 2001; Gray et al., 2005; Hiyoshi et al., 2005), microporous zeolites and mesoporous molecular sieves (Takamura et al., 2001; Siriwardane et al., 2003; Son et al., 2008; Zelenak et al., 2008a), and microporous metal-organic framework materials (MOFs) (Torrisi et al., 2010; Zhang Z. et al., 2013; Gonzalez-Zamora and Ibrra, 2017).

Zeolites are widely used in refinery and gas separation industry, and have shown high $\mathrm{CO}_{2}$ uptake such as zeolite $13 \mathrm{X}$ and $\mathrm{Ca}-\mathrm{A}$, reaching about 3 and $3.72 \mathrm{mmol} / \mathrm{g}$, respectively (Bae et al., 2013). $\mathrm{CO}_{2}$ adsorption over zeolites is derived from the interaction between the electric field of zeolite and the large quadrupole moment of $\mathrm{CO}_{2}$. Thus, both the structure and composition of zeolite framework, and the composition and location of cations govern its $\mathrm{CO}_{2}$ adsorption performance (Grajciar et al., 2012; Kim et al., 2012). Lin et al. screened over hundreds of thousands of zeolites and zeolitic imidazolate frameworks (ZIFs) via a computational approach and identified potential materials for $\mathrm{CO}_{2}$ capture (Lin et al., 2012). The main weakness of zeolites is their sensitivity to moisture, which results in a significant reduction of $\mathrm{CO}_{2}$ uptake (Bui et al., 2018).

MOFs are a relatively new class of crystalline porous materials constructed via self-assemblage of metal "nodes" and organic linkers (Long and Yaghi, 2009; Zhou et al., 2012; Lu et al., 2014). MOFs possess very high surface areas and pore volumes. Theoretically, by varying the metal and the linker, infinite different MOFs can be synthesized, and their physicochemical properties are consequently tuned in terms of $\mathrm{CO}_{2}$ capacity, selectivity, and heat of adsorption, which makes them highly attractive for $\mathrm{CO}_{2}$ capture (Singh et al., 2020). For example, MOF-74(Mg) showed a high $\mathrm{CO}_{2}$ adsorption capacity of $5.5 \mathrm{mmol} / \mathrm{g}$ at 0.15 bar $\mathrm{CO}_{2}$ and $40^{\circ} \mathrm{C}$ (Caskey et al., 2008; Bae et al., 2013), while UiO-66 and SIFSIX-6_Zn exhibited good resistance to other flue gas components such as water, $\mathrm{SO}_{\mathrm{x}}$, and $\mathrm{NO}_{\mathrm{x}}$ (Nugent et al., 2013; Burtch et al., 2014; Wang C. et al., 2016). In a recent article, Ding et al. conducted a comprehensive review on MOFs for $\mathrm{CO}_{2}$ capture and conversion, where they summarized and compared the reported MOFs for $\mathrm{CO}_{2}$ capture in terms of their $\mathrm{CO}_{2}$ capacities (Ding et al., 2019).

Carbon materials including activated carbons, carbon nanotubes, and graphene have also been studied for $\mathrm{CO}_{2}$ capture due to their low cost and wide availability (Wang Q. et al., 2011; Montagnaro et al., 2015; Taheri Najafabadi, 2015; Mohamedali et al., 2016). The capability of carbon materials for $\mathrm{CO}_{2}$ adsorption mainly relies on its porosity; thus, the higher the pore volume, particularly the micropores, the higher the $\mathrm{CO}_{2}$ capacity (Estevez et al., 2018). Carbons work better at high pressure. While at low pressure, their $\mathrm{CO}_{2}$ capacities are typically lower than those of zeolites. Compared to zeolites, carbons possess much better stability in the presence of water (Xu et al., 2013).

Another type of solid adsorbents is oxides including $\mathrm{CaO}$, $\mathrm{MgO}$, and FeO (Feng et al., 2007; Florin and Harris, 2009; Mutch 


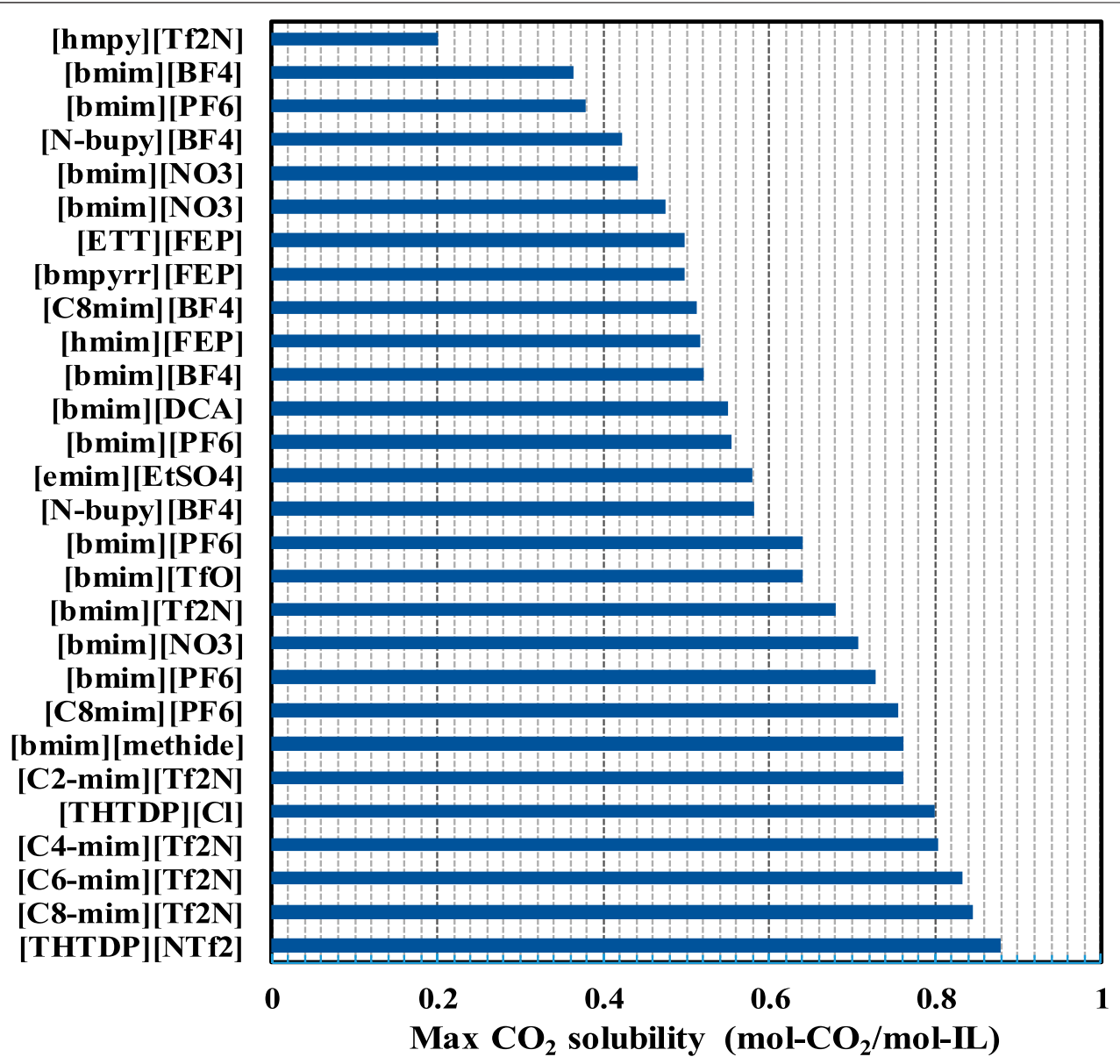

FIGURE 5 | The reported maximum $\mathrm{CO}_{2}$ absorption capacity of some typical ionic liquids for $\mathrm{CO}_{2}$ capture at $40^{\circ} \mathrm{C}$ with $\mathrm{CO}_{2}$ partial pressure of $15 \mathrm{kPa}$, data from the literature (Zhang et al., 2008; Pérez-Salado Kamps et al., 2003; Shiflett and Yokozeki, 2005; Shin et al., 2008; Carvalho et al., 2010; Kilaru and Scovazzo, 2008; Anderson et al., 2007; Aki et al., 2004; Blanchard et al., 2001).

et al., 2018; Mora Mendoza et al., 2019); layered double hydroxides (LDHs) (Ram Reddy et al., 2006; Ram Reddy et al., 2008); and alkali metal-containing ceramics such as $\mathrm{Li}_{2} \mathrm{ZrO}_{3}$ (Nakagawa, 1998), $\mathrm{Li}_{4} \mathrm{SiO}_{4}$ (Gauer and Heschel, 2006), and $\mathrm{Na}_{2} \mathrm{SiO}_{3}$ (Rodríguez and Pfeiffer, 2008). Those adsorbents are normally handled at high temperatures within the cyclic carbonation/calcination reactors. High temperature $\left(>500^{\circ} \mathrm{C}\right.$ ) causes the sintering of oxides, which results in the dramatic reduction of their $\mathrm{CO}_{2}$ capture performance (Erans et al., 2016).

Compared to abovementioned adsorbents, amine-based solid sorbents are the center of investigation in adsorption. Since the first report on polyethylenimine (PEI)-based sorbents showing good performance for $\mathrm{CO}_{2}$ separation, the so-called molecular basket sorbents (Figure 6) (Xu et al., 2002), in the past twenty years, solid sorbents containing amines, have aroused significant interests for $\mathrm{CO}_{2}$ capture and later for $\mathrm{CO}_{2}$ removal directly from air (Yu et al., 2012). The use of amine-functionalized sorbents can greatly reduce the need in the parasitic energy input (mainly because solid has lower heat capacity than water), and offer high $\mathrm{CO}_{2}$ capacity and selectivity, fast kinetics, multicycle stability, and tolerance to water with no or less corrosion to the equipment (Ma et al., 2009; Choi et al., 2009; Wang et al., 2009; Bollini et al., 2011; Wang and Song, 2019). By far, three popular approaches are proceeding in preparation of those amine-based sorbents, which are outlined in Figure 6, including 1) immobilizing amine compounds (e.g., PEI, TEPA, DEA, and dendrimers (Wang et al., 2005; Yue et al., 2006; Liang et al., 2008; Qi et al., 2011)) onto a nanoporous support (Xu et al., 2002; Xu et al., 2003; Xu et al., 2005; Ma et al., 2009; Chen et al., 2010; Liu et al., 2010; Tanthana and Chuang, 2010; Wang D. et al., 2011; Zhang et al., 2012; Yang et al., 2013) and/or microporous zeolites (Kim et al., 2016) and MOFs (Demessence et al., 2009; Lee et al., 2014; McDonald et al., 2015) by a conventional wet impregnation method; 2) growing reactive amine monomers inside the porous material via in situ polymerization method or incorporating amine compounds with silica precursor during mesoporous material preparation via co-condensation method (Tsuda et al., 1992; Tsuda and Fujiwara, 1992; Rosenholm et al., 2006; Rosenholm and Linden, 2007; Hicks et al., 2008); and 3) covalently grafting amine compounds (e.g., (3-aminopropyl) trimethoxysilane and (3-aminopropyl)triethoxysilane) on a 


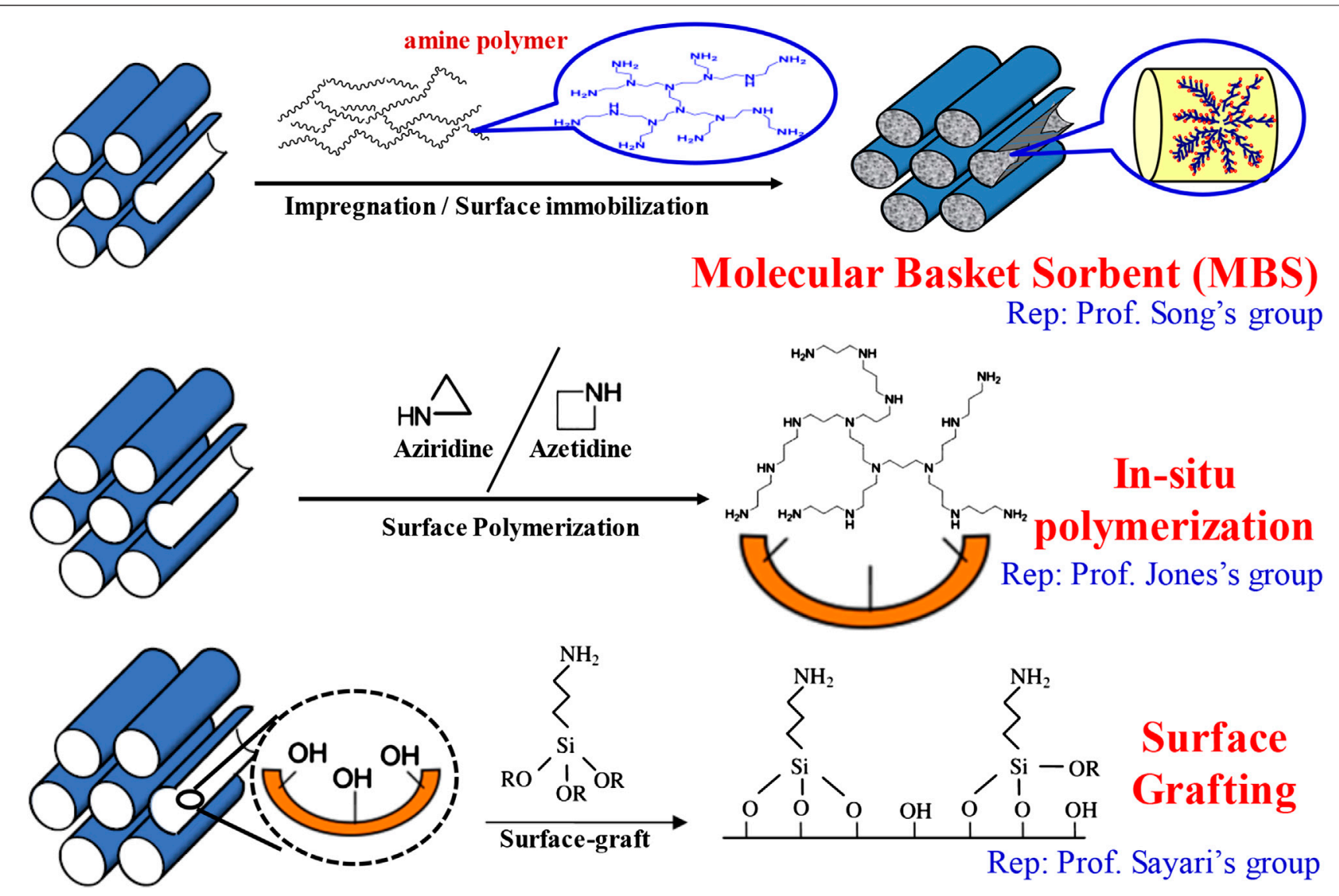

FIGURE 6 | Schematic illustration of the widely used three approaches in preparation of the amine-based sorbents.

support surface via post-synthesis method (Huang et al., 2003; Hiyoshi et al., 2004; Hiyoshi et al., 2005; Zelenak et al., 2008b; Belmabkhout and Sayari, 2009; Kumar and Guliants, 2010).

Polymer PEI contains repeating $-\mathrm{CH}_{2} \mathrm{CH}_{2}-\mathrm{NH}$-units. Because it has high nitrogen content in mass and relatively good thermal stability (Yue et al., 2008; Goeppert et al., 2011), PEI is often selected for amine-based sorbents, becoming a promising candidate suitable not only for $\mathrm{CO}_{2}$ capture from flue gases with relatively high $\mathrm{CO}_{2}$ concentration, but also good for direct air capture. Other amines such as tetraethylenepentamine (TEPA), pentaethylenehexamine (PEHA), MEA, DEA, and diisopropanolamine are more prone to leaching issue due to their relatively low molecular weight and boiling points, which could cause $\mathrm{CO}_{2}$ capacity loss and pollute the downstream equipment of the sorption system (Goeppert et al., 2014). Many reviews on solidsorbent-based $\mathrm{CO}_{2}$ capture have been published (Song, 2006; SanzPérez et al., 2016; Darunte et al., 2016; Choi et al., 2009; D’Alessandro et al., 2010; Lin et al., 2016; Didas et al., 2015; Dutcher et al., 2015; Chen C. et al., 2014; Gargiulo et al., 2014; Olajire, 2017). In a recent book chapter (Wang and Song, 2019), we summarized the recent advances of solid PEI-based sorbents for $\mathrm{CO}_{2}$ capture focusing on the development of sorbent materials, the mechanism and kinetics in $\mathrm{CO}_{2}$ sorption, the regeneration and deactivation, and the current and future $\mathrm{CO}_{2}$ capture approaches.
To have a better overall picture, the $\mathrm{CO}_{2}$ capacities reported in the literature with different support at different PEI loading and sorption temperature for $\mathrm{CO}_{2}$ capture from pure $\mathrm{CO}_{2}$ and the

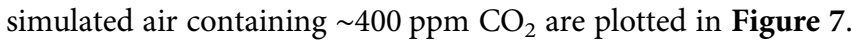
For $\mathrm{CO}_{2}$ capture from pure $\mathrm{CO}_{2}$ (Figure 7A), the higher the PEI loading, the higher the $\mathrm{CO}_{2}$ uptake. Increasing temperature also benefits $\mathrm{CO}_{2}$ sorption. Generally, high $\mathrm{CO}_{2}$ capture capacity of around $150-200 \mathrm{mg} / \mathrm{g}$ is mostly reported, which is favored at $50-70$ wt.\% PEI loading at $70-90^{\circ} \mathrm{C}$. The amine efficiency (termed as A.E.), which is defined as moles of $\mathrm{CO}_{2}$ captured per mole of $\mathrm{N}$ groups in the sorbent, is presented as an inset in Figure 7A. It shows the major value of about 0.30 (the black dot line in the inset of Figure 7A). It is widely accepted that under dry condition, two $\mathrm{N}$ sites are needed for one $\mathrm{CO}_{2}$ molecule through the formation of zwitterions. Although tertiary amine does not directly react with $\mathrm{CO}_{2}$, it could accept the proton from zwitterions generated by the reactions between $\mathrm{CO}_{2}$ and primary/secondary amines, contributing to $\mathrm{CO}_{2}$ sorption. Thus, it is projected that the theoretic value for the maximum amine efficiency would be 0.5 (the blue dot line in the inset of Figure 7A). Clearly, most PEI-based sorbents are still not able to achieve this theoretic value, although there are a few reports showing their amine efficiency close to 0.5 . Only one article reported the amine efficiency over 0.5 , which was attributed to the contribution of 

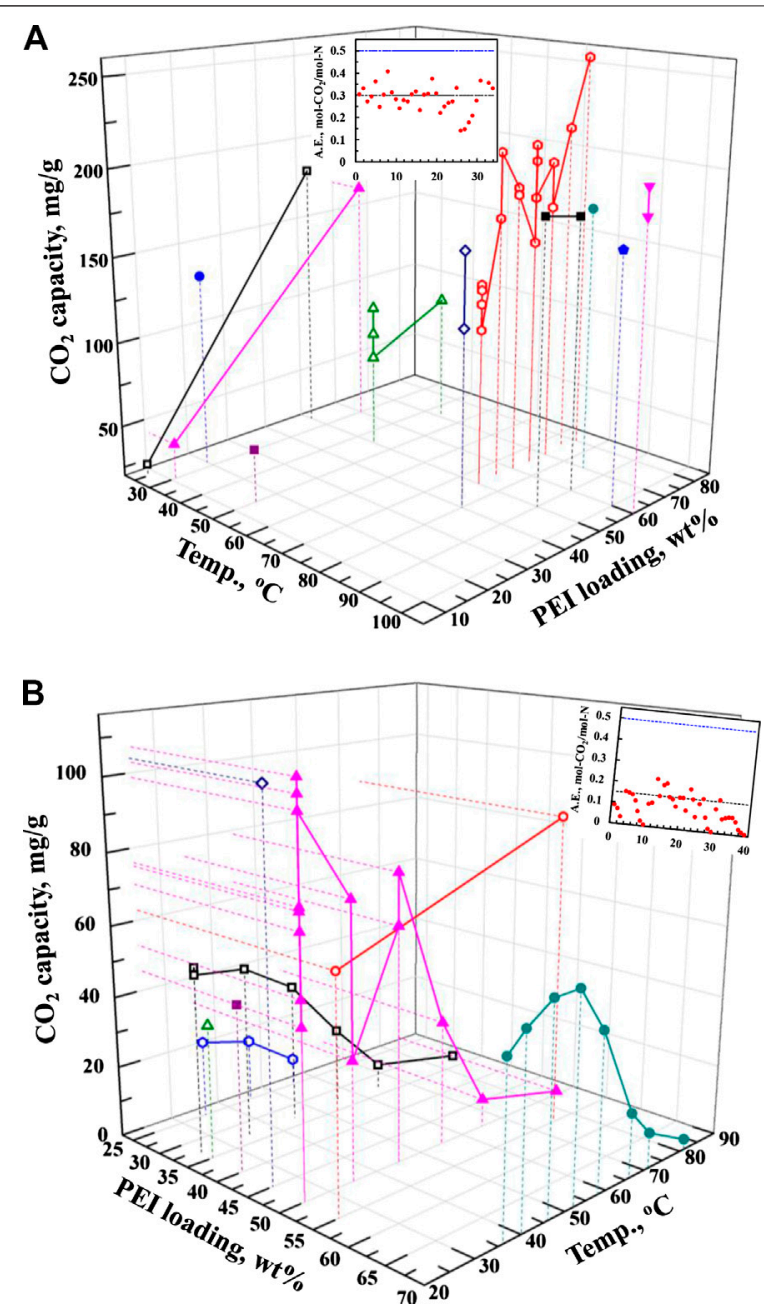

FIGURE 7 $\mid \mathrm{CO}_{2}$ capacity reported in the literature with different support at different PEl loading and temperature for $\mathrm{CO}_{2}$ capture from (A) pure $\mathrm{CO}_{2}$ and (B) from simulated air with about $400 \mathrm{ppm} \mathrm{CO}_{2}$ along with the insets showing the amine efficiency (A.E., mol- $\mathrm{CO}_{2} / \mathrm{mol}-\mathrm{N}$ ). All data are from the reported values (Wang and Song, 2019).

$\mathrm{CO}_{2}$ physisorption on the porous support (Gaikwad et al., 2019). As for the air capture (Figure 7B), most work was studied over the sorbents with PEI loading of $50 \mathrm{wt} . \%$ at room temperature. Unlike $\mathrm{CO}_{2}$ capture from pure $\mathrm{CO}_{2}$, increasing temperature results in the decrease of $\mathrm{CO}_{2}$ uptake, making it suitable for air capture operation. Compared to those amine efficiency for pure $\mathrm{CO}_{2}$, the amine efficiency for air capture is much lower, in between 0.05 and 0.15 . It reflects that $\mathrm{CO}_{2}$ capture directly from the air is more challenging than that from the concentrated $\mathrm{CO}_{2}$ sources.

Figure 7 displays an indication of the current development status of the PEI-based solid sorbents. Considering the low amine efficiency compared to the theoretic value, especially for the air capture, we believe there is still a possibility to further enhance $\mathrm{CO}_{2}$ capture from both the concentrated sources and the air. Thus, further investigations are required to determine at what level of PEI dispersion could be best for maximizing the amine efficiency with high capacity, or whether there is a limit in the amine efficiency in order to maintain the best $\mathrm{CO}_{2}$ sorption capacity and kinetics.

With the aid of modern and advanced characterization techniques, the $\mathrm{CO}_{2}$ sorption/deactivation mechanism over PEI-based sorbents has been fundamentally better understood. Zhang et al. studied $\mathrm{CO}_{2}$ sorption behavior with small angle neutron scattering (SANS) technique and identified that the swelling of PEI with $\mathrm{CO}_{2}$ sorption and temperature increase played an important role in $\mathrm{CO}_{2}$ sorption process (Zhang et al., 2019). Using solid-state nuclear magnetic resonance (SSNMR), Mafra et al. (Mafra et al., 2017) found three chemisorbed $\mathrm{CO}_{2}$ species involving hydrogen bonds with either surface silanols or amines. Chen et al. (2018) confirmed the formation of bicarbonate in the presence of water. During $\mathrm{CO}_{2}$ sorption, both carbamate and carbamic acid are formed (Foo et al., 2017; Shimon et al., 2018), but only carbamic acid desorbs while carbamate persists (Shimon et al., 2018). The formation of $\mathrm{C}=\mathrm{O}$ and $-\mathrm{CH}=\mathrm{N}$ - species is a main reason for the air degradation of amine sorbents (Ahmadalinezhad and Sayari, 2014). To improve the regeneration and long-term stability of PEI-based sorbents, a two-step synthesis strategy involving support modification followed by PEI loading has been proposed and studied (Choi et al., 2016; Jeon et al., 2018; Min et al., 2018a; Min et al., 2018b; Xu et al., 2018; Kim et al., 2019; Wang et al., 2020), which have been summarized and elaborated in our recent book chapter (Wang and Song, 2019).

Additionally, there has been important progress in the development of adsorption processes for $\mathrm{CO}_{2}$ capture. A large number of different cyclic regeneration processes using temperature, pressure, vacuum, steam or moisture, or combinations thereof have been studied. Recently, Inventys Inc. (now is Svante Inc.) reported the VeloxoTherm ${ }^{\mathrm{TM}}$ process using a rotary unit packed with structured honeycomb adsorbent for both $\mathrm{CO}_{2}$ adsorption and desorption, which can complete a full cycle in about $60 \mathrm{~s}$ (Greeson, 2016). The comprehensively review of the development of these processes can be found in the literature (Grande and Rodrigues, 2008; Webley, 2014).

It should be pointed out that with the advance of the technologies, some novel structured $\mathrm{CO}_{2}$ adsorbents have emerged, such as thin film nanocomposites (Shah and Imae, 2016; Yong, 2016; Niranjana et al., 2019) and adsorbent-coated monoliths made of zeolites, MOFs, or carbons (Öhrman et al., 2004; Ramos-Fernandez et al., 2011; Akhtar et al., 2014; Lee et al., 2015). Monolithic contactors have substantial advantages like uniform flow, high gas throughput, low pressure drop, and less attrition in comparison with conventional packed-bed reactors (Rezaei and Webley, 2009; Rezaei and Webley, 2010). Both the diameter of the parallel channels and the density per crosssectional area of monoliths are controllable. Most recently, three-dimensional (3D) printing or additive manufacturing technique has gained worldwide attention and has been applied for fabrication of 3D-printed monoliths including zeolites (e.g., 5A and 13X) and MOFs (MOF-74-Ni and UTSA-16-Co (Thakkar et al., 2016; Thakkar et al., 2017a; Thakkar et al., 2017b; Thakkar et al., 2018; Nguyen et al., 2019; Regufe et al., 2019; Thompson et al., 2019). Compared 
to those prepared by conventional method, the 3D-printed adsorbent materials exhibited comparable $\mathrm{CO}_{2}$ capacity, fast adsorption rate, and relative stability and regenerability. Although 3D-printing shows flexibility in material design and requires less steps and resources, extensive study on fabricating the adsorbent materials at large scale for carbon capture is needed.

\section{Membrane}

Compared to other separation methods, membrane separation is generally more energy efficient and environmentally benign, thus has been much studied for $\mathrm{CO}_{2}$ removal from flue gases (Merkel et al., 2010; Japip et al., 2014). In membrane separation, the driving force is the pressure and/or concentration difference. The higher the pressure difference, the better the membrane separation. Therefore, it is more applicable to pre-combustion capture processes, while it is quite challenging for postcombustion capture due mainly to the low $\mathrm{CO}_{2}$ partial pressure and/or concentration in the post-combustion flue gases. Furthermore, unlike other methods, membrane separation involves multistage operation and streams recycling, which makes this method more complicated and complex.

Based on the properties of the fabrication materials, there are three types of membranes in general (Powell and Qiao, 2006; Low et al., 2013): inorganic (or ceramic), organic (or polymeric), and hybrid membranes. Those made up of zeolites, oxides (e.g., $\mathrm{Al}_{2} \mathrm{O}_{3}, \mathrm{TiO}_{2}$, and $\mathrm{ZrO}_{2}$ ), ceramics, carbons, and MOFs are typical inorganic membranes (Al-Mamoori et al., 2017). Inorganic membranes are capable of high temperature operation with good mechanical stability, but high fabrication cost limits their scale-up (Al-Mamoori et al., 2017). Compared to inorganic membranes, polymeric membranes have several advantages including ease of synthesis, low production cost, good mechanical stability, and excellent separation performance (Songolzadeh et al., 2014). Thus, more and more polymeric membranes are practically replacing inorganic membranes in large-scale industrial gas separation processes (Bernardo et al., 2009), and gradually dominating most commercial membranes (Siagian et al., 2019). However, their thermal stability is relatively low, which curbs their application in post-combustion $\mathrm{CO}_{2}$ capture. Flue gases normally have to be cooled down first for membrane process (Du et al., 2011; Favre, 2011). The separation performance of polymeric membrane materials can be further improved by incorporating or blending organic or inorganic compounds (Du et al., 2011; Dai et al., 2019).

Recently, new types of polymeric membranes have been developed, for example, thermally rearranged (TR) and intrinsic microporosity polymeric (PIM) membranes. TR membranes exhibit improved thermal stability through structural rearrangement and molecular transformation during the heat treatment, which can generate interconnected microcavities with narrow size distribution, decreasing the mechanical strength of TR membranes (Jo et al., 2015; Liu Q. et al., 2016; Scholes, 2016). PIM membranes are promising for $\mathrm{CO}_{2}$ capture as they exhibit high $\mathrm{CO}_{2}$ permeability and selectivity, surpassing the Robeson's upper bond due largely to their pore structure, thus receiving much attention (Alaslai et al., 2016; Yong et al., 2016; Gemeda et al., 2017). Siagian et al. compared various polymeric membranes in terms of $\mathrm{CO}_{2} / \mathrm{N}_{2}$ selectivity vs. the permeability (Siagian et al., 2019). The conventional polymers are not able to reach the desired performance for $\mathrm{CO}_{2}$ separation. The performance of TR membranes is close to the Robeson's upper bond, while some of PIM membranes show the performance above the Robeson's upper value, suggesting PIM membranes are more promising than TR membranes for $\mathrm{CO}_{2}$ removal. However, more tests are needed for these new membranes to be practical for $\mathrm{CO}_{2}$ capture in industries.

Hybrid membrane, or mixed matrix membrane (MMM), which normally consists of an inorganic component such as zeolites, carbon nanotubes, silicates, alumina, or MOFs incorporated into the polymer matrix in the nanoparticles form (Vinoba et al., 2017; Ahmad et al., 2018; Sarfraz and BaShammakh, 2018; Dilshad et al., 2019; Julian et al., 2019), is becoming a new trend to improve polymeric membranes' properties, as it could possess both advantages of inorganic and organic materials. Incorporating inorganic particles improves both the mechanical and thermal properties, making the polymeric membranes more stable. Thus, it provides a solution to go beyond the restraint of polymeric membranes and the inherent drawbacks of inorganic membranes in cost and production (Ramasubramanian et al., 2012; Tanh Jeazet et al., 2012; Bae and Long, 2013). MMM membranes show the potential to exceed the Robeson's upper value and are comparable to the PIM membranes. The main drawback for MMM membranes is that inorganic particles could be poorly dispersed, even aggregated within the polymer matrix, leading to membrane defects, deteriorating its overall performance (Zhang Y. et al., 2013; Siagian et al., 2019). In addition, they are under early development along with costly and complex fabrication processes (Ramasubramanian and Ho, 2011).

A new type of MMM membranes called facilitated transport hybrid membranes (FTHMs) or fixed carrier membranes (FCMs) has been proposed and studied (Wu et al., 2014). By incorporating the polymeric matrix with functional groups, it exhibits fairly high $\mathrm{CO}_{2}$ permeability, $\mathrm{CO}_{2}$ selectivity, and material stability (Wang S. et al., 2016), thus is promising as next-generation membrane for $\mathrm{CO}_{2}$ separation. For example, at $107^{\circ} \mathrm{C}$ and $15 \mathrm{bar}$, the $\mathrm{CO}_{2}$ permeability and the $\mathrm{CO}_{2} / \mathrm{N}_{2}$ selectivity of the FCM containing amino-functionalized multiwall carbon nanotubes was 975 Barrer and 384, respectively (Ansaloni et al., 2015). The $\mathrm{CO}_{2}$ permeance of $5693 \mathrm{GPU}$ and $\mathrm{CO}_{2} / \mathrm{N}_{2}$ selectivity of 268 were reported over the FCM incorporated with nanosized hydrotalcite in PEI-epichlorohydrin copolymer (PEIE) at around $25^{\circ} \mathrm{C}$ and 1.1 bar (Liao et al., 2014). Similar to other MMM membranes, one of the biggest challenges for industrial application of FCMs is to prepare the membranes without defects and the use of nanosized carriers without agglomeration.

Besides the membrane materials, the configuration of membrane modules is also crucial. There are four main types of modular configurations mostly adopted: tubular, plate-andframe (Martín, 2016; Berk, 2018), spiral wound (Qi and Henson, 
1998; Chen X. et al., 2015; Liu C. et al., 2016), and hollow fiber (Yoshimune and Haraya, 2013; Chen X. et al., 2015; Esposito et al., 2015; Liu C. et al., 2016). Compared to other types of modules, hollow-fiber membranes exhibit better popularity and more compact because of its optimum geometry and high surface-to-volume ratio (Koros, 2004; Al-Mamoori et al., 2017; Wang Y. et al., 2017). Furthermore, highly porous polymeric substructures supporting a thin selective layer of hollow fiber membranes show the potential in advancing the development of membranes (Chen H. et al., 2014).

\section{FUTURE CONSIDERATION OF CARBON CAPTURE TECHNOLOGIES}

\section{Combination of Flue Gas Recycling and Hybrid Capture}

The current development of $\mathrm{CO}_{2}$ capture processes has largely centered on a single separation technology. Although numerous optimizations in materials and processes have been pursued, implementing a single separation process (e.g., aqueous aminebased chemical absorption) is either energy intensive or costly. Only few studies have looked at integrating two or more technologies (i.e., absorption, adsorption, membrane, and cryogenic) into a hybrid process for $\mathrm{CO}_{2}$ capture (Freeman et al., 2014). The integration of different separation technologies could avoid their individual disadvantages, thus may be superior to the standalone process (Scholz et al., 2013).

Recently, Song et al. reviewed the hybrid $\mathrm{CO}_{2}$ capture technologies and explored possible combinations (Song et al., 2018), including absorption-, adsorption-, membrane-, and cryogenic-based hybrid processes with different options. Nakhiiri and Heydarinasab compared the performance of the hybrid membrane absorption process using ethylenediamine (EDA), 2-(1-piperazinyl)-ethylamine (PZEA), and potassium sarcosinate (PS) absorbents (Nakhjiri and Heydarinasab, 2019). They found that the $\mathrm{CO}_{2}$ separation efficiency decreases as PZEA > PS > EDA. Atlaskin et al. (Atlaskin et al., 2020) studied a hybrid membrane-assisted gas absorption (MAGA) process for $\mathrm{CO}_{2}$ and $\mathrm{H}_{2} \mathrm{~S}$ removal. The efficiency for $\mathrm{CO}_{2} / \mathrm{H}_{2} \mathrm{~S}$ separation was significantly increased by mixing imidazolium ionic liquid (ca. $5 \mathrm{v}$ $\%$ ) into the methyldiethanolamine (MDEA) solution. Over the hybrid membrane absorption system using 2-methylpiperazine (2MPZ)-promoted potassium carbonate for $\mathrm{CO}_{2}$ separation, increasing $2 \mathrm{MPZ}$ concentration, absorbent flow rate, porosity to tortuosity ratio, and membrane fibers can enhance the $\mathrm{CO}_{2}$ removal percentage up to over $98 \%$ (Izaddoust and Keshavarz, 2017; Mesbah et al., 2019). Scholes et al. recently reported the pilot plant trials with hollow fiber membrane-MEA (MEA, $30 \mathrm{wt}$ \%) contactor for post-combustion $\mathrm{CO}_{2}$ capture, showing the energy duty less than $4.2 \mathrm{GJ} /$ ton of $\mathrm{CO}_{2}$ captured (Scholes et al., 2020). Through the comparison to the standalone methods, they found that the hybrid processes are superior in terms of $\mathrm{CO}_{2}$ recovery, energy penalty, and installation investment, thus are promising as future carbon capture technology (Song et al., 2018).
As above-pointed out, the high energy penalty for $\mathrm{CO}_{2}$ capture process is mainly caused by the low concentration or partial pressure of $\mathrm{CO}_{2}$ in a flue gas, which results in high cost for CCS, as the capture step accounts for about $70-80 \%$ of the overall CCS cost (Figueroa et al., 2008). As shown in Table 2, the typical $\mathrm{CO}_{2}$ concentration in flue gases is about $3-14 \%$. The current prevail economic analysis estimates a cost of $\$ 70-100 /$ tonne- $\mathrm{CO}_{2}$ for carbon capture from flue gas (Vitillo et al., 2017). With only $400 \mathrm{ppm} \mathrm{CO}_{2}$ in air, a DACC process requires a cost between $\$ 300$ and $\$ 1,500$ per tonne of $\mathrm{CO}_{2}$ captured (National Academies of Sciences, Engineering, and Medicine, 2019). One viable strategy is to increase the partial pressure or concentration of $\mathrm{CO}_{2}$ in flue gas. For example, through exhaust gas recycling, in which flue gas from natural gas boiler (containing $~ 4 \% \mathrm{CO}_{2}$ ) is recycled and used in place of air for the fuel combustion, $\mathrm{CO}_{2}$ concentration in the flue gas can be enriched up to $\sim 8 \%$, making $\mathrm{CO}_{2}$ capture less thermodynamically challenging (Vaccarelli et al., 2014). However, considering the significant capital investment in exhaust gas recycling with respect to the combustion unit, the balance between exhaust gas recycling and carbon capture energy penalty has to be carefully and thoroughly examined and optimized (Vaccarelli et al., 2014).

Membranes can also be utilized to concentrate $\mathrm{CO}_{2}$ from flue gas for recycling. Merkel et al. obtained up to $20 \%$ increase in $\mathrm{CO}_{2}$ concentration and up to $40 \%$ reduction in the minimum energy required for $\mathrm{CO}_{2}$ capture (Merkel et al., 2013). A set of membranes in series or parallel may be used for selective $\mathrm{CO}_{2}$ recycling, offering increased driving force for $\mathrm{CO}_{2}$ separation. It could be more efficient if coupled with other capture technologies (e.g., absorption, adsorption, and cryogenics), especially with those hybrid systems.

Although it could increase capital and maintenance costs, recycling flue gas or pre-concentrating $\mathrm{CO}_{2}$ with membranes can simplify the $\mathrm{CO}_{2}$ capture process. By combining the advantages of hybrid $\mathrm{CO}_{2}$ capture systems, we believe that the benefits in the subsequent $\mathrm{CO}_{2}$ capture step could be substantial, which may ultimately make this approach more energy efficient and cost effective. Although currently the experimental data are not enough, the primary results have convinced us that the proposed concept would be plausible as future CCS direction, especially to overcome the technical bottlenecks encountered when using single carbon capture technology.

\section{One-Step Integrated $\mathrm{CO}_{2}$ Capture and Conversion}

Another encouraging strategy is integrating the $\mathrm{CO}_{2}$ capture and conversion in one stage. In nature, organisms or organelles indeed systematically utilize and store $\mathrm{CO}_{2}$ directly. However, compared to chemical-based approaches, they are much limited by the long time and large contact area requirements (Table 3 ). When $\mathrm{CO}_{2}$ capture is integrated directly with subsequent in situ $\mathrm{CO}_{2}$ utilization/conversion to value-added products in one step, the concept of which is depicted in Figure 8, the process could eliminate the needs of the steps for $\mathrm{CO}_{2}$ desorption, compression, transportation, and storage, eradicating the energy penalty associated with these steps. It is particularly useful to the 


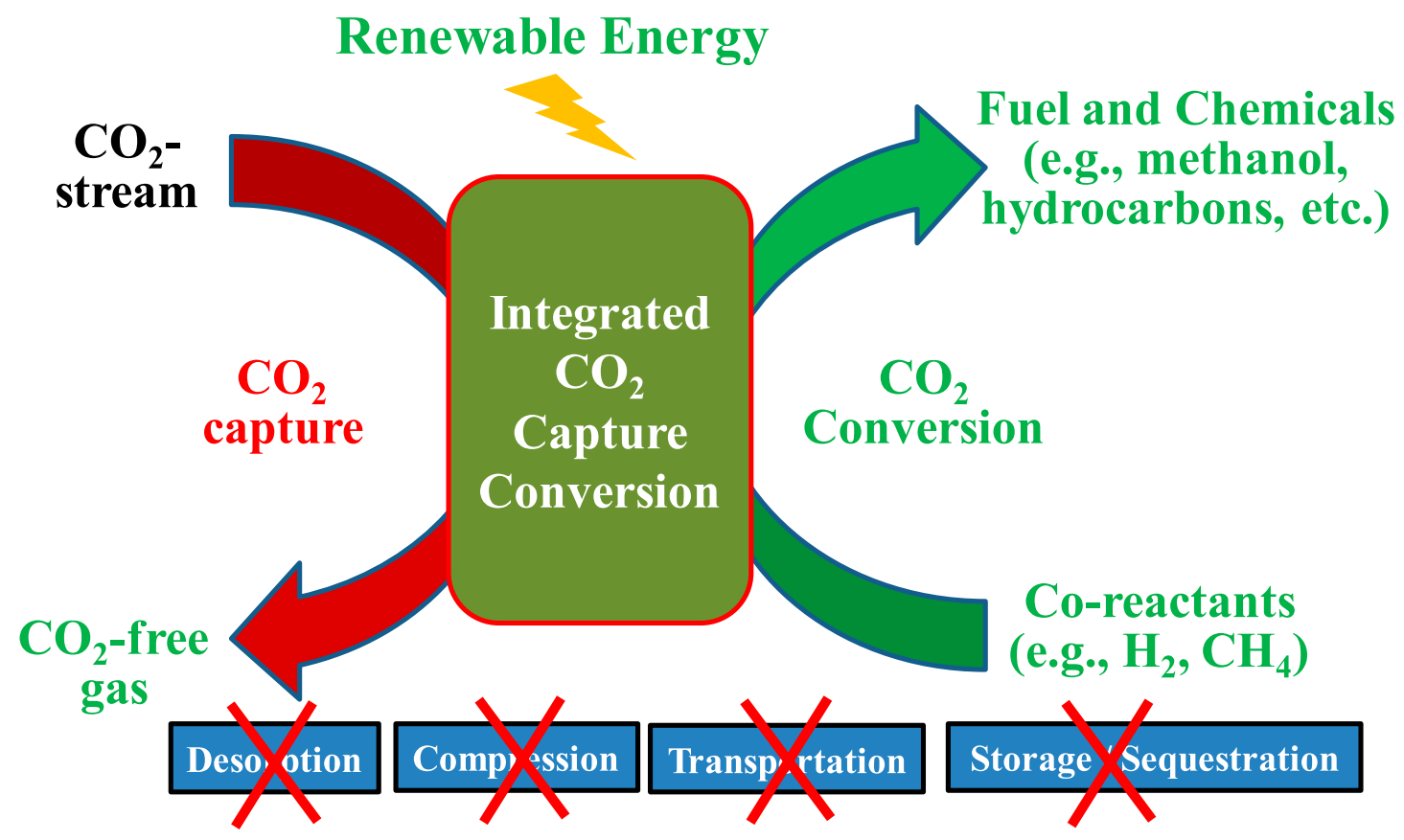

FIGURE 8 | Concept of one step direct integration of $\mathrm{CO}_{2}$ capture and in situ $\mathrm{CO}_{2}$ conversion.

chemical absorption-based $\mathrm{CO}_{2}$ capture technologies, where the significant energy penalty occurs at the desorption step. Furthermore, the production of value-added chemicals and fuels could generate revenues to compensate the cost for carbon capture, which helps reducing the economic barrier for the commercial deployment of the $\mathrm{CO}_{2}$ capture technologies. This is also a pathway to functionalizing metal-organic frameworks, electrocatalysts, photocatalysts, and more-for their potential applications in $\mathrm{CO}_{2}$ capture and conversion.

Recent years, more reports about the one-step integration of $\mathrm{CO}_{2}$ capture and conversion are coming out. Gassner and Leitner first reported the attempt to integrate catalytic $\mathrm{CO}_{2}$ conversion to capture via $\mathrm{CO}_{2}$ hydrogenation to formate in the presence of aqueous amine solutions (Gassner and Leitner, 1993). He et al. explored a combined system containing a superbase, a poly (ethylene glycol) (PEG), ionic liquid and amino acid for in situ $\mathrm{CO}_{2}$ capture-conversion to carbonates, urea, and formate salts (Yang et al., 2011a; Yang et al., 2011b; Liu et al., 2012). Kim et al. experimentally demonstrated a process directly integrating $\mathrm{CO}_{2}$ utilization into $\mathrm{CO}_{2}$ capture, allowing for the full conversion of the $\mathrm{CO}_{2}$ captured into syngas in a single reactor using limestone for $\mathrm{CO}_{2}$ capture and a non-precious metal catalyst for $\mathrm{CO}_{2}$ conversion with $\mathrm{CH}_{4}$ (Kim et al., 2018). Liu et al. developed a novel hybrid $\mathrm{MgAl}(\mathrm{LDO}) / \mathrm{TiO}_{2}$ adsorbent/ photocatalyst for the integrated $\mathrm{CO}_{2}$ capture plus photocatalytic conversion directly to $\mathrm{Cl}$ products at $100-200^{\circ} \mathrm{C}$ (Liu et al., 2015). The regeneration of the developed material can be easily achieved with low-grade waste heat and/or solar energy (Liu et al., 2015). Kar et al. systematically reviewed the current progress in the integrated capture-conversion process using aqueous amine and hydroxide solutions for $\mathrm{CO}_{2}$ capture followed by in situ hydrogenation using coexisted homogeneous metal complex catalysts to formate salts and methanol (Kar et al., 2019). The whole process is regenerable for multiple cycles. Consequently, they suggested that the amineassisted $\mathrm{CO}_{2}$ capture and conversion to methanol process is very encouraging. Stuardi et al. also suggested the integration of $\mathrm{CO}_{2}$ capture and utilization as a priority research direction (Marocco Stuardi et al., 2019).

Besides the liquid amine processes, the solid adsorbent catalyst-based $\mathrm{CO}_{2}$ capture-conversion processes using dual function materials (DFMs) consisting of the methanation catalyst (e.g., $\mathrm{Ru}$ and $\mathrm{Ni}$ ) and $\mathrm{CO}_{2}$ adsorbent (e.g., $\mathrm{CaO}$, $\mathrm{Na}_{2} \mathrm{O}$, and $\mathrm{MgO}$ ) on a support have also been studied at mild conditions $\left(200-350^{\circ} \mathrm{C}\right.$ and $\left.1 \mathrm{~atm}\right)$ (Duyar et al., 2015; Duyar et al., 2016; Miguel et al., 2017; Wang S. et al., 2017; Wang et al., 2018; Arellano-Treviño et al., 2019; Zhou et al., 2020).Those DFMs exhibit stable performance in $\mathrm{CO}_{2}$ capture and conversion to synthetic $\mathrm{CH}_{4}$ for over 50 cycles. No loss in $\mathrm{CO}_{2}$ capture capacity and $\mathrm{Ru}$ dispersion was observed (Wang et al., 2018). Over the 2D-layered $\mathrm{Ni}-\mathrm{MgO}-\mathrm{Al}_{2} \mathrm{O}_{3}$ nanosheets, continuous and nearly $100 \%$ capture of $\mathrm{CO}_{2}$ during prolonged cycling tests was achieved at temperatures below $250^{\circ} \mathrm{C}$ (Zhou et al., 2020). Its hydrogen efficiency reached $60 \%$ for $\mathrm{CO}_{2}$ conversion to $\mathrm{CH}_{4}$, making the process attractive for large $\mathrm{CO}_{2}$ emission sources.

Patterson et al. proposed an approach to recycle atmospheric $\mathrm{CO}_{2}$ into liquid fuels on a large-scale marine-based artificial island, using renewable energy (solar or wind) to power the production of hydrogen and $\mathrm{CO}_{2}$ extraction from seawater, followed by catalytic conversion to liquid methanol fuel (Patterson et al., 2019). The major advantage of the proposed 
approach is the utilization of sea as the $\mathrm{CO}_{2}$ absorber, in which it is always in equilibrium with the atmosphere, along with the usage of renewable energy, generating negative $\mathrm{CO}_{2}$ emission through the process.

These efforts in the integration of $\mathrm{CO}_{2}$ capture and conversion in one step have demonstrated their promise, although mainly $\mathrm{C} 1$ products are generated. Through the research entailing experimental results coupled with theory to improve fundamental understanding, and the design of innovative polyfunctional and multi-structured materials for the one-step integrated $\mathrm{CO}_{2}$ capture and conversion, the production of liquid hydrocarbon fuels, chemicals, polymers, carbon materials (e.g., nanotubes and nanofibers) directly from flue gas or atmospheric $\mathrm{CO}_{2}$ can be envisaged in future. It will also lead to developing carbon capture technologies with smaller size, greener process, and better energy efficiency. If implemented, it could significantly change the way in $\mathrm{CO}_{2}$ capture, compress, transport, conversion, and/or storage, thus increasing opportunities for $\mathrm{CO}_{2}$ valorization, and offer a feasible solution to the current global environmental problems associated with energy use.

\section{CONCLUDING REMARKS}

Through the past few decades of research and development, there have been significant progresses in $\mathrm{CO}_{2}$ capture technologies, but still far from economically attractive commercialization. It requires a comprehensive investigation on the characteristics and relationships of the materials and process performance, which is crucial to the development of next-generation carbon

\section{REFERENCES}

Aaron, D. and Tsouris, C. (2005). Separation of $\mathrm{CO}_{2}$ from flue gas: a review. Sep. Sci. Technol. 40, 321-348. doi:10.1081/SS-200042244

Abanades, J. C., Arias, B., Lyngfelt, A., Mattisson, T., Wiley, D. E., Li, H., et al. (2015). Emerging $\mathrm{CO}_{2}$ capture systems. Int. J. Greenh. Gas Control. 40, 126-166. doi:10.1016/j.ijggc.2015.04.018

Adanez, J., Abad, A., Garcia-Labiano, F., Gayan, P., and de Diego, L. F. (2012). Progress in chemical-looping combustion and reforming technologies. Prog. Energy Combust. Sci. 38, 215-282. doi:10.1016/j.pecs.2011.09.001

Ahmad, M. Z, Navarro, M., Lhotka, M., Zornoza, B., Téllez, C., de Vos, W. M., et al. (2018). Enhanced gas separation performance of 6FDA-DAM based mixed matrix membranes by incorporating MOF UiO-66 and its derivatives. J. Membr. Sci. 558, 64-77. doi:10.1016/j.memsci.2018.04.040

Ahmadalinezhad, A. and Sayari, A. (2014). Oxidative degradation of silicasupported polyethylenimine for $\mathrm{CO}_{2}$ adsorption: insights into the nature of deactivated species. Phys. Chem. Chem. Phys. 16, 1529-1535. doi:10.1039/ c3cp53928h

Akhtar, F., Keshavarzi, N., Shakarova, D., Cheung, O., Hedin, N., and Bergström, L. (2014). Aluminophosphate monoliths with high $\mathrm{CO}_{2}$-over- $\mathrm{N}_{2}$ selectivity and $\mathrm{CO}_{2}$ capture capacity. RSC Adv. 4, 55877-55883. doi:10.1039/ C4RA05009F

Aki, S. N. V. K., Mellein, B. R., Saurer, E. M., and Brennecke, J. F. (2004). Highpressure phase behavior of carbon dioxide with imidazolium-based ionic liquids. J. Phys. Chem. B 108, 20355-20365. doi:10.1021/jp046895

Alaslai, N., Ghanem, B., Alghunaimi, F., and Pinnau, I. (2016). High-performance intrinsically microporous dihydroxyl-functionalized triptycene-based polyimide for natural gas separation. Polymer 91, 128-135. doi:10.1016/j. polymer.2016.03.063 capture technologies with improved energy efficiency and costeffectiveness. In this perspective, we believe the two plausible approaches, that is, the combination of flue gas recycling and hybrid capture system, and one-step integration of $\mathrm{CO}_{2}$ capture and conversion, are promising for future research, as they could offer significant improvement in energy efficiency and costeffectiveness, by simplifying the capture process in the former and eliminating the desorption, compression, transportation, and storage steps in the latter, respectively. However, more research and development such as materials development, synergistic assessment, process design, process optimization, and scale-up are required. Their environmental impacts and the life-cycle analysis should also be considered. Nonetheless, the proposed and emerging approaches appear to be promising with better commercial potential in the future, and offer a viable solution to the technical bottlenecks of current carbon capture technologies, and to the global dilemma in meeting more energy demand while reducing environmental impact.

\section{AUTHOR CONTRIBUTIONS}

All authors listed have made a substantial, direct, and intellectual contribution to the work and approved it for publication.

\section{ACKNOWLEDGMENTS}

The financial support from the Pennsylvania State University and EMS Energy Institute Seed Grant is appreciatively acknowledged.

Al-Mamoori, A., Krishnamurthy, A., Rownaghi, A. A., and Rezaei, F. (2017). Carbon capture and utilization update. Energy Technol. 5, 834-849. doi:10. 1002/ente.201600747

Anderson, J. L., Dixon, J. K., and Brennecke, J. F. (2007). Solubility of $\mathrm{CO}_{2}, \mathrm{CH}_{4}$, $\mathrm{C}_{2} \mathrm{H}_{6}, \quad \mathrm{C}_{2} \mathrm{H}_{4}, \quad \mathrm{O}_{2}, \quad$ and $\quad \mathrm{N}_{2}$ in 1-hexyl-3-methylpyridinium bis(trifluoromethylsulfonyl)imide: comparison to other ionic liquids. Accounts Chem. Res. 40, 1208-1216. doi:10.1021/ar7001649

Ansaloni, L., Zhao, Y., Jung, B. T., Ramasubramanian, K., Baschetti, M. G., and Ho, W. S. W. (2015). Facilitated transport membranes containing aminofunctionalized multi-walled carbon nanotubes for high-pressure $\mathrm{CO}_{2}$ separations. J. Membr. Sci. 490, 18-28. doi:10.1016/j.memsci.2015.03.097

Arellano-Treviño, M. A., He, Z., Libby, M. C., and Farrauto, R. J. (2019). Catalysts and adsorbents for $\mathrm{CO}_{2}$ capture and conversion with dual function materials: limitations of Ni-containing DFMs for flue gas applications. J. $\mathrm{CO}_{2}$ Util. 31, 143-151. doi:10.1016/j.jcou.2019.03.009

Arshad, M. W., Svendsen, H. F., Fosbøl, P. L., Von Solms, N., and Thomsen, K. (2014). Equilibrium total pressure and $\mathrm{CO}_{2}$ solubility in binary and ternary aqueous solutions of 2-(Diethylamino)ethanol (DEEA) and 3-(Methylamino) propylamine (MAPA). J. Chem. Eng. Data 59, 764-774. doi:10.1021/je400886w

Atlaskin, A. A., Kryuchkov, S. S., Yanbikov, N. R., Smorodin, K. A., Petukhov, A. N., Trubyanov, M. M., et al. (2020). Comprehensive experimental study of acid gases removal process by membrane-assisted gas absorption using imidazolium ionic liquids solutions absorbent. Sep. Purif. Technol. 239, 116578. doi:10.1016/ j.seppur.2020.116578

Azarabadi, H. and Lackner, K. S. (2020). Postcombustion capture or direct air capture in decarbonizing US natural gas power? Environ. Sci. Technol. 54, 5102-5111. doi:10.1021/acs.est.0c00161

Bae, T.-H. and Long, J. R. (2013). $\mathrm{CO}_{2} / \mathrm{N}_{2}$ separations with mixed-matrix membranes containing $\mathrm{Mg} 2$ (dobdc) nanocrystals. Energy Environ. Sci. 6, 3565-3569. doi:10.1039/c3ee42394h 
Bae, T.-H., Hudson, M. R., Mason, J. A., Queen, W. L., Dutton, J. J., Sumida, K., et al. (2013). Evaluation of cation-exchanged zeolite adsorbents for postcombustion carbon dioxide capture. Energy Environ. Sci. 6, 128-138. doi:10. 1039/C2EE23337A

Bates, E. D., Mayton, R. D., Ntai, I., and Davis, J. H. (2002). $\mathrm{CO}_{2}$ capture by a taskspecific ionic liquid. J. Am. Chem. Soc. 124, 926-927. doi:10.1021/ja017593d

Belmabkhout, Y. and Sayari, A. (2009). Effect of pore expansion and amine functionalization of mesoporous silica on $\mathrm{CO}_{2}$ adsorption over a wide range of conditions. Adsorpt.-J. Int. Adsorpt. Soc. 15, 318-328. doi:10.1007/s10450009-9185-6

Benamor, A. and Aroua, M. K. (2005). Modeling of $\mathrm{CO}_{2}$ solubility and carbamate concentration in DEA, MDEA and their mixtures using the DeshmukhMather model. Fluid Phase Equil. 231, 150-162. doi:10.1016/j.fluid.2005.02. 005

Berk, Z. (2018). "Membrane processes," in Food process engineering and technology. 3rd Edn, Editors Z. Berk (Cambridge, MA: Academic Press), Chap. 10, 261-287

Bernardo, P., Drioli, E., and Golemme, G. (2009). Membrane gas separation: a review/state of the art. Ind. Eng. Chem. Res. 48, 4638-4663. doi:10.1021/ ie8019032

Bhown, A. S., Bromhal, G., and Barki, G. (2020). " $\mathrm{CO}_{2}$ capture and sequestration," in Fossil energy. Editors R. Malhotra (New York, NY: Springer), 503-517

Blanchard, L. A., Gu, Z., and Brennecke, J. F. (2001). High-pressure phase behavior of ionic liquid/ $\mathrm{CO}_{2}$ systems. J. Phys. Chem. B 105, 2437-2444. doi:10.1021/ jp003309d

Bollini, P., Didas, S. A., and Jones, C. W. (2011). Amine-oxide hybrid materials for acid gas separations. J. Mater. Chem. 21, 15100-15120. doi:10.1039/ C1JM12522B

Bougie, F. and Iliuta, M. C. (2014). Solubility of $\mathrm{CO}_{2}$ in and density, viscosity, and surface tension of aqueous 2-amino-1,3-propanediol (serinol) solutions. J.Chem. Eng. Data 59, 355-361. doi:10.1021/je4008298

Brovkin, V., Sitch, S., Von Bloh, W., Claussen, M., Bauer, E., and Cramer, W. (2004). Role of land cover changes for atmospheric $\mathrm{CO}_{2}$ increase and climate change during the last 150 years. Global Change Biol. 10, 1253-1266. doi:10. 1111/j.1365-2486.2004.00812.x

Bui, M., Adjiman, C. S., Bardow, A., Anthony, E. J., Boston, A., Brown, S., et al. (2018). Carbon capture and storage (CCS): the way forward Energy Environ. Sci. 11, 1062-1176. doi:10.1039/c7ee02342a

Burtch, N. C., Jasuja, H., and Walton, K. S. (2014). Water stability and adsorption in metal-organic frameworks. Chem. Rev. 114, 10575-10612. doi:10.1021/ cr5002589

Carbon Engineering (2020). Carbon engineering website. Available at: https:// carbonengineering.com/ (Accessed July 15, 2020).

Carvalho, P. J., Álvarez, V. H., Schröder, B., Gil, A. M., Marrucho, I. M., Aznar, M., et al. (2009). Specific solvation interactions of $\mathrm{CO}_{2}$ on acetate and trifluoroacetate imidazolium based ionic liquids at high pressures. J. Phys. Chem. B 113, 6803-6812. doi:10.1021/jp901275b

Carvalho, P. J., Álvarez, V. H., Marrucho, I. M., Aznar, M., and Coutinho, J. A. P. (2010). High carbon dioxide solubilities in trihexyltetradecylphosphoniumbased ionic liquids. J. Supercrit. Fluids 52, 258-265. doi:10.1016/j.supflu.2010. 02.002Get

Caskey, S. R., Wong-Foy, A. G., and Matzger, A. J. (2008). Dramatic tuning of carbon dioxide uptake via metal substitution in a coordination polymer with cylindrical pores. J. Am. Chem. Soc. 130, 10870-10871. doi:10.1021/ja8036096

Chakma, A. (1999). Formulated solvents: new opportunities for energy efficient separation of acid gases. Energy Sources 21, 51-62. doi:10.1080/ 00908319950014957

Chang, Y. C., Leron, R. B., and Li, M. H. (2013). Equilibrium solubility of carbon dioxide in aqueous solutions of (diethylenetriamine + piperazine). J. Chem. Thermodyn. 64, 106-113. doi:10.1016/j.jct.2013.05.005

Chatterjee, S. and Huang, K.-W. (2020). Unrealistic energy and materials requirement for direct air capture in deep mitigation pathways. Nat. Commun. 11, 3287. doi:10.1038/s41467-020-17203-7

Chen, X. and Rochelle, G. T. (2011). Aqueous piperazine derivatives for $\mathrm{CO}_{2}$ capture: accurate screening by a wetted wall column. Chem. Eng. Res. Des. 89, 1693-1710. doi:10.1016/j.cherd.2011.04.002

Chen, C., Son, W. J., You, K. S., Ahn, J. W., and Ahn, W. S. (2010). Carbon dioxide capture using amine-impregnated HMS having textural mesoporosity. Chem. Eng. J. 161, 46-52. doi:10.1016/j.cej.2010.04.019
Chen, C., Kim, J., and Ahn, W. S. (2014). $\mathrm{CO}_{2}$ capture by amine-functionalized nanoporous materials: a review. Korean J. Chem. Eng. 31, 1919-1934. doi:10. 1007/s11814-014-0257-2

Chen, H. Z., Thong, Z., Li, P., and Chung, T.-S. (2014). High performance composite hollow fiber membranes for $\mathrm{CO}_{2} / \mathrm{H}_{2}$ and $\mathrm{CO}_{2} / \mathrm{N}_{2}$ separation. Int. J. Hydrog. Energy 39, 5043-5053. doi:10.1016/j.ijhydene.2014.01.047

Chen, S., Chen, S., Fei, X., Zhang, Y., and Qin, L. (2015). Solubility and characterization of $\mathrm{CO}_{2}$ in 40 mass \% $\mathrm{N}$-ethylmonoethanolamine solutions: explorations for an efficient nonaqueous solution. Ind. Eng. Chem. 54, 7212-7218. doi:10.1021/acs.iecr.5b01654

Chen, X. Y., Vinh-Thang, H., Ramirez, A. A., Rodrigue, D., and Kaliaguine, S. (2015). Membrane gas separation technologies for biogas upgrading. RSC $A d v$. 5, 24399-24448. doi:10.1039/C5RA00666J

Chen, C.-H., Shimon, D., Lee, J. J., Mentink-Vigier, F., Hung, I., Sievers, C., et al. (2018). The "missing" bicarbonate in $\mathrm{CO}_{2}$ chemisorption reactions on solid amine sorbents. J. Am. Chem. Soc. 140, 8648-8651. doi:10.1021/jacs.8b04520

Choi, S., Drese, J. H., and Jones, C. W. (2009). Adsorbent materials for carbon dioxide capture from large anthropogenic point sources. ChemSusChem 2, 796-854. doi:10.1002/cssc.200900036

Choi, W., Min, K., Kim, C., Ko, Y. S., Jeon, J. W., Seo, H., et al. (2016). Epoxidefunctionalization of polyethyleneimine for synthesis of stable carbon dioxide adsorbent in temperature swing adsorption. Nat. Commun. 7, 12640. doi:10. 1038 /ncomms 12640

Chu, S. (2009). Carbon capture and sequestration. Science 325, 1599. doi:10.1126/ science.1181637

Climeworks (2020). Climeworks website. Available at: http://www.climeworks.com (Accessed July 15, 2020).

Conway, W., Bruggink, S., Beyad, Y., Luo, W., Melián-Cabrera, I., Puxty, G., et al. (2015). $\mathrm{CO}_{2}$ absorption into aqueous amine blended solutions containing monoethanolamine (MEA), N,N-dimethylethanolamine (DMEA), N,Ndiethylethanolamine (DEEA) and 2-amino-2-methyl-1-propanol (AMP) for post-combustion capture processes. Chem. Eng. Sci. 126, 446-454. doi:10.1016/ j.ces.2014.12.053

Corvo, M. C., Sardinha, J., Casimiro, T., Marin, G., Seferin, M., Einloft, S., et al., (2015). A rational approach to $\mathrm{CO}_{2}$ capture by imidazolium ionic liquids: tuning $\mathrm{CO}_{2}$ solubility by cation alkyl branching, ChemSusChem, 8 1935-1946.doi:10.1002/cssc.201500104

Cousins, A., Nielsen, P. T., Huang, S., Rowland, R., Edwards, B., Cottrell, A., et al. (2015). Pilot-scale evaluation of concentrated piperazine for $\mathrm{CO}_{2}$ capture at an Australian coal-fired power station: nitrosamine measurements. Int. J. Greenh. Gas Control 37, 256-263. doi:10.1016/j.ijggc.2015.03.007

Cui, G., Wang, J., and Zhang, S. (2016). Active chemisorption sites in functionalized ionic liquids for carbon capture. Chem. Soc. Rev. 45, 4307-4339. doi:10.1039/c5cs00462d

Cullinane, J. T. and Rochelle, G. T. (2006). Kinetics of carbon dioxide absorption into aqueous potassium carbonate and piperazine. Ind. Eng. Chem. Res. 45, 2531-2545. doi:10.1021/ie050230s

Dai, Z., Deng, J., Aboukeila, H., Yan, J., Ansaloni, L., Mineart, K. P., et al. (2019). Highly $\mathrm{CO}_{2}$-permeable membranes derived from a midblock-sulfonated multiblock polymer after submersion in water. NPG Asia Mater. 11, 53. doi:10.1038/s41427-019-0155-5

D'Alessandro, D. M., Smit, B., and Long, J. R. (2010). Carbon dioxide capture: prospects for new materials. Angew. Chem. Int. Ed. 49, 6058-6082. doi:10.1002/ anie. 201000431

Darunte, L. A., Walton, K. S., Sholl, D. S., and Jones, C. W., (2016). $\mathrm{CO}_{2}$ capture via adsorption in amine-functionalized sorbents. Curr. Opin. Chem. Eng. 12, 82-90. doi:10.1016/j.coche.2016.03.002

de Riva, J., Suarez-Reyes, J., Moreno, D., Díaz, I., Ferro, V., and Palomar, J. (2017). Ionic liquids for post-combustion $\mathrm{CO}_{2}$ capture by physical absorption: thermodynamic, kinetic and process analysis. Int. J. Greenh. Gas Control 61, 61-70. doi:10.1016/j.ijggc.2017.03.019

Demessence, A., D’Alessandro, D. M., Foo, M. L., and Long, J. R. (2009). Strong $\mathrm{CO}_{2}$ binding in a water-stable, triazolate-bridged Metal-Organic framework functionalized with ethylenediamine. J. Am. Chem. Soc. 131, 8784-8786. doi:10. $1021 / \mathrm{ja} 903411 \mathrm{w}$

Derks, P. W. J., Dijkstra, H. B. S., Hogendoorn, J. A., and Versteeg, G. F. (2005). Solubility of carbon dioxide in aqueous piperazine solutions. AIChE J. 51, 2311-2327. doi:10.1002/aic.10442 
Didas, S. A., Choi, S., Chaikittisilp, W., and Jones, C. W. (2015). Amine-oxide hybrid materials for $\mathrm{CO}_{2}$ capture from ambient air. Accounts Chem. Res. 48, 2680-2687. doi:10.1021/acs.accounts.5b00284

Dilshad, M. R., Islam, A., Hamidullah, U., Jamshaid, F., Ahmad, A., Butt, M. T. Z., et al. (2019). Effect of alumina on the performance and characterization of cross-linked PVA/PEG 600 blended membranes for $\mathrm{CO}_{2} / \mathrm{N}_{2}$ separation. Sep. Purif. Technol. 210, 627-635. doi:10.1016/j.seppur.2018.08.026

Ding, Y. and Alpay, E. (2000). Equilibria and kinetics of $\mathrm{CO}_{2}$ adsorption on hydrotalcite adsorbent. Chem. Eng. Sci. 55, 3461-3474. doi:10.1016/S00092509(99)00596-5

Ding, M., Flaig, R. W., Jiang, H.-L., and Yaghi, O. M. (2019). Carbon capture and conversion using metal-organic frameworks and MOF-based materials. Chem. Soc. Rev. 48, 2783-2828. doi:10.1039/c8cs00829a

Du, N., Park, H. B., Robertson, G. P., Dal-Cin, M. M., Visser, T., Scoles, L., et al. (2011). Polymer nanosieve membranes for $\mathrm{CO}_{2}$-capture applications. Nature Mater. 10, 372-375. doi:10.1038/nmat2989

Dugas, R. E. and Rochelle, G. T. (2011). $\mathrm{CO}_{2}$ absorption rate into concentrated aqueous monoethanolamine and piperazine. J. Chem. Eng. Data 56, 2187-2195. doi:10.1021/je101234t

Dutcher, B., Fan, M. H., and Russell, A. G. (2015). Amine-based $\mathrm{CO}_{2}$ capture technology development from the beginning of 2013-A review. ACS Appl. Mater. Interfaces 7, 2137-2148. doi:10.1021/am507465f

Duyar, M. S., Treviño, M. A. A., and Farrauto, R. J. (2015). Dual function materials for $\mathrm{CO}_{2}$ capture and conversion using renewable $\mathrm{H}_{2}$. Appl. Catal. B 168-169, 370-376. doi:10.1016/j.apcatb.2014.12.025

Duyar, M. S., Wang, S., Arellano-Treviño, M. A., and Farrauto, R. J. (2016). $\mathrm{CO}_{2}$ utilization with a novel dual function material (DFM) for capture and catalytic conversion to synthetic natural gas: an update. J. $\mathrm{CO}_{2}$ Util. 15, 65-71. doi:10. 1016/j.jcou.2016.05.003

El Hadri, N., Quang, D. V., Goetheer, E. L. V., and Abu Zahra, M. R. M. (2017). Aqueous amine solution characterization for post-combustion $\mathrm{CO}_{2}$ capture process. Appl. Energy 185, 1433-1449. doi:10.1016/j.apenergy. 2016.03.043

Erans, M., Manovic, V., and Anthony, E. J. (2016). Calcium looping sorbents for $\mathrm{CO}_{2}$ capture. Appl. Energy 180, 722-742. doi:10.1016/j.apenergy.2016.07.074

Esposito, E., Clarizia, G., Bernardo, P., Jansen, J. C., Sedláková, Z., Izák, P., et al. (2015). Pebax ${ }^{\circledR} / \mathrm{PAN}$ hollow fiber membranes for $\mathrm{CO}_{2} / \mathrm{CH}_{4}$ separation. Chem. Eng. Process. 94, 53-61. doi:10.1016/j.cep.2015.03.016

Estevez, L., Barpaga, D., Zheng, J., Sabale, S., Patel, R. L., Zhang, J.-G., et al. (2018). Hierarchically porous carbon materials for $\mathrm{CO}_{2}$ capture: the role of pore structure. Ind. Eng. Chem. Res. 57, 1262-1268. doi:10.1021/acs.iecr.7b03879

Pérez-Salado Kamps, Á., Tuma, D., Xia, J., and Maurer, G. (2003). Solubility of $\mathrm{CO}_{2}$ in the ionic liquid [bmim][PF6]. J Chem. Eng. Data 48, 746-749. doi:10.1021/ je034023f

Fan, L. S. (2010). Chemical looping systems for fossil energy conversions. Hoboken, NJ: John Wiley \& Sons

Favre, E. (2011). Membrane processes and postcombustion carbon dioxide capture: challenges and prospects. Chem. Eng. J. 171, 782-793. doi:10.1016/j.cej.2011.01. 010

Feng, B., An, H., and Tan, E. (2007). Screening of $\mathrm{CO}_{2}$ adsorbing materials for zero emission power generation systems. Energy Fuels 21, 426-434. doi:10.1021/ ef0604036

Feron, P. H. M. and Hendriks, C. A. (2005). $\mathrm{CO}_{2}$ capture process principles and costs. Oil \& Gas Sci. Tech. - Rev. IFP 60, 451-459. doi:10.2516/ogst:2005027

Figueroa, J. D., Fout, T., Plasynski, S., McIlvried, H., and Srivastava, R. D. (2008). Advances in $\mathrm{CO}_{2}$ capture technology-the U.S. Department of energy's carbon sequestration program. Int. J. Greenh. Gas Control 2, 9-20. doi:10.1016/S17505836(07)00094-1

Florin, N. H. and Harris, A. T. (2009). Reactivity of $\mathrm{CaO}$ derived from nano-sized $\mathrm{CaCO}_{3}$ particles through multiple $\mathrm{CO}_{2}$ capture-and-release cycles. Chem. Eng. Sci. 64, 187-191. doi:10.1016/j.ces.2008.10.021

Foo, G. S., Lee, J. J., Chen, C.-H., Hayes, S. E., Sievers, C., and Jones, C. W. (2017). Elucidation of surface species through in Situ FTIR spectroscopy of carbon dioxide adsorption on amine-grafted SBA-15. ChemSusChem 10, 266-276. doi:10.1002/cssc.201600809

Freeman, S. A., Davis, J., and Rochelle, G. T. (2010a). Degradation of aqueous piperazine in carbon dioxide capture. Int. J. Greenh. Gas Control 4, 756-761. doi:10.1016/j.ijggc.2010.03.009
Freeman, S. A., Dugas, R., Van Wagener, D. H., Nguyen, T., and Rochelle, G. T. (2010b). Carbon dioxide capture with concentrated, aqueous piperazine. Int. J. Greenh. Gas Control 4, 119-124. doi:10.1016/j.ijggc.2009.10.008

Freeman, B., Hao, P., Baker, R., Kniep, J., Chen, E., Ding, J., et al. (2014). Hybrid membrane-absorption $\mathrm{CO}_{2}$ capture process. Energy Procedia 63, 605-613. doi:10.1016/j.egypro.2014.11.065

Gaikwad, S., Kim, S.-J., and Han, S. (2019). $\mathrm{CO}_{2}$ capture using aminefunctionalized bimetallic MIL-101 MOFs and their stability on exposure to humid air and acid gases. Micropor. Mesopor. Mat. 277, 253-260. doi:10.1016/j. micromeso.2018.11.001

Gargiulo, N., Pepe, F., and Caputo, D. (2014). $\mathrm{CO}_{2}$ adsorption by functionalized nanoporous materials: a review. J. Nanosci. Nanotechnol. 14, 1811-1822. doi:10. 1166/jnn.2014.8893

Gassner, F. and Leitner, W. (1993). Hydrogenation of carbon dioxide to formic acid using water-soluble rhodium catalyststs. J. Chem. Soc., Chem. Commun. 1465-1466. doi:10.1039/C39930001465

Gauer, C. and Heschel, W. (2006). Doped lithium orthosilicate for absorption of carbon dioxide. J. Mater. Sci. 41, 2405-2409. doi:10.1007/s10853-006-7070-1

Gazzani, M., Macchi, E., and Manzolini, G. (2013a). $\mathrm{CO}_{2}$ capture in integrated gasification combined cycle with SEWGS - Part A: thermodynamic performances. Fuel 105, 206-219. doi:10.1016/j.fuel.2012.07.048

Gazzani, M., Macchi, E., and Manzolini, G. (2013b). $\mathrm{CO}_{2}$ capture in natural gas combined cycle with SEWGS. Part A: thermodynamic performances. Int. J. Greenh. Gas Control 12, 493-501. doi:10.1016/j.ijggc.2012.06.010

Gemeda, A. E., De Angelis, M. G., Du, N., Li, N., Guiver, M. D., and Sarti, G. C. (2017). Mixed gas sorption in glassy polymeric membranes. III. $\mathrm{CO}_{2} / \mathrm{CH}_{4}$ mixtures in a polymer of intrinsic microporosity (PIM-1): effect of temperature. J. Membr. Sci. 524, 746-757. doi:10.1016/j.memsci.2016.11.053

Giernoth, R. (2010). Task-specific ionic liquids. Angew. Chem. Int. Ed. 49, 2834-2839. doi:10.1002/anie.200905981

Global Thermostat (2020). Global Thermostat website. Available at: https:// globalthermostat.com/ (Accessed July 15, 2020).

Goeppert, A., Czaun, M., May, R. B., Prakash, G. K. S., Olah, G. A., and Narayanan, S. R. (2011). Carbon dioxide capture from the air using a polyamine based regenerable solid adsorbent. J. Am. Chem. Soc. 133, 20164-20167. doi:10.1021/ ja2100005

Goeppert, A., Czaun, M., Surya Prakash, G. K., and Olah, G. A. (2012). Air as the renewable carbon source of the future: an overview of $\mathrm{CO}_{2}$ capture from the atmosphere. Energy Environ. Sci. 5, 7833-7853. doi:/10.1039/C2EE21586A

Goeppert, A., Zhang, H., Czaun, M., May, R. B., Prakash, G. K. S., Olah, G. A., et al. (2014). Easily regenerable solid adsorbents based on polyamines for carbon dioxide capture from the air. ChemSusChem 7, 1386-1397. doi:10.1002/cssc. 201301114

Gomez, A., Briot, P., Raynal, L., Broutin, P., Gimenez, M., Soazic, M., et al. (2014). ACACIA project - development of a post-combustion $\mathrm{CO}_{2}$ capture process. Case of the DMXTM Process. Oil Gas Sci. Technol. - Rev. IFP Energies nouvelles 69, 1121-1129. doi:10.2516/ogst/2014035

Gonzalez-Zamora, E. and Ibrra, I. A. (2017). $\mathrm{CO}_{2}$ capture under humid conditions in metal-organic frameworks. Mater. Chem. Front. 1, 1471-1484. doi:10.1039/ C6QM00301J

Grajciar, L., Čejka, J., Zukal, A., Otero Areán, C., Turnes Palomino, G., and Nachtigall, P. (2012). Controlling the adsorption enthalpy of $\mathrm{CO}_{2}$ in zeolites by framework topology and composition. ChemSusChem 5, 2011-2022. doi:10. 1002/cssc. 201200270

Grande, C. A. and Rodrigues, A. E. (2008). Electric Swing Adsorption for $\mathrm{CO}_{2}$ removal from flue gases. Int. J. Greenh Gas Control 2, 194-202. doi:10.1016/ S1750-5836(07)00116-8

Gray, M. L., Soong, Y., Champagne, K. J., Pennline, H., Baltrus, J. P., Stevens, R. W., et al. (2005). Improved immobilized carbon dioxide capture sorbents, Fuel Process. Technol. 86, 1449-1455. doi:10.1016/j.fuproc.2005.01.005

Greeson, D. (2016). NRG $\mathrm{CO}_{2} \mathrm{NCEPT}$ - confirmation of novel cost-effective emerging post-combustion technology. DE-FE0026581 Final Technical Report. Report NO. 81.089. https://www.netl.doe.gov/sites/default/files/201712/fe0026581-final-report.pdf.

Hallett, J. P. and Welton, T. (2011). Room-temperature ionic liquids: solvents for synthesis and catalysis. 2. Chem. Rev. 111. 3508-3576. doi:10.1021/cr1003248

Haszeldine, R. S. (2009). Carbon capture and storage: how green can black Be? Science 325, 1647-1652. doi:10.1126/science.1172246 
Hicks, J. C., Drese, J. H., Fauth, D. J., Gray, M. L., Qi, G. G., and Jones, C. W. (2008). Designing adsorbents for $\mathrm{CO}_{2}$ capture from flue gas-hyperbranched aminosilicas capable of capturing $\mathrm{CO}_{2}$ reversibly. J. Am. Chem. Soc. 130, 2902-2903. doi:10.1021/ja077795v

Hiyoshi, N., Yogo, K., and Yashima, T. (2004). Adsorption of carbon dioxide on amine modified SBA15 in the presence of water vapor. Chem. Lett. 33, 510-511. doi:10.1246/cl.2004.510

Hiyoshi, N., Yogo, K., and Yashima, T. (2005). Adsorption characteristics of carbon dioxide on organically functionalized SBA-15. Micropor. Mesopor. Mat 84, 357-365. doi:10.1016/j.micromeso.2005.06.010

Houghton, J. T., Ding, Y., Griggs, D. J., Noguer, M., Linden, P. J. v. d., Dai, X., et al. (2001). Climate change 2001: the scientific basis. Cambridge, UK: Cambridge University Press

Huang, H. Y., Yang, R. T., Chinn, D., and Munson, C. L. (2003). Amine-grafted MCM-48 and silica xerogel as superior sorbents for acidic gas removal from natural gas. Ind. Eng. Chem. Res. 42, 2427-2433. doi:10.1021/ie020440u

Huang, L. L., Zhang, L. Z., Shao, Q., Lu, L. H., Lu, X. H., Jiang, S. Y., et al. (2007). Simulations of binary mixture adsorption of carbon dioxide and methane in carbon nanotubes: temperature, pressure, and pore size effects. J. Phys. Chem. C 111, 11912-11920. doi:10.1021/jp067226u

Husebye, J., Brunsvold, A. L., Roussanaly, S., and Zhang, X. (2012). Techno economic evaluation of amine based $\mathrm{CO}_{2}$ capture: impact of $\mathrm{CO}_{2}$ concentration and steam supply. Energy Procedia 23, 381-390. doi:10.1016/j. egypro.2012.06.053

IEA (2010). Energy Technology Perspectives (2010): Scenarios and strategies to 2050. Paris: OECD

IPCC (2015). Climate change 2014 synthesis report summary for Policymakers. Available at: https://www.ipcc.ch/pdf/assessment-report/ar5/syr/AR5_SYR_ FINAL_SPM.pdf

Ishida, M. and Jin, H. (1994). A novel combustor based on chemical-looping reactions and its reaction kinetics. J. Chem. Eng. JPN. 27, 296-301. doi:10.1252/ jcej.27.296

Ishida, M., Zheng, D., and Akehata, T. (1987). Evaluation of a chemical-loopingcombustion power-generation system by graphic exergy analysis. Energy 12, 147-154. doi:10.1016/0360-5442(87)90119-8

Izaddoust, A. and Keshavarz, P. (2017). Experimental and theoretical study of $\mathrm{CO}_{2}$ absorption with piperazine-promoted potassium carbonate solution in hollow fiber membrane contactors. Energy Fuels 31, 9790-9799. doi:10.1021/acs. energyfuels.7b01554

Jansen, D., Gazzani, M., Manzolini, G., Dijk, E. v., and Carbo, M. (2015). Precombustion $\mathrm{CO}_{2}$ capture. Int. J. Greenh. Gas Control 40, 167-187. doi:10.1016/j. ijggc.2015.05.028

Japip, S., Wang, H., Xiao, Y., and Shung Chung, T. (2014). Highly permeable zeolitic imidazolate framework (ZIF)-71 nano-particles enhanced polyimide membranes for gas separation. J. Membr. Sci. 467, 162-174. doi:10.1016/j. memsci.2014.05.025

Jeon, S., Jung, H., Kim, S. H., and Lee, K. B. (2018). Double-layer structured $\mathrm{CO}_{2}$ adsorbent functionalized with modified polyethyleneimine for high physical and chemical stability. ACS Appl. Mater. Interfaces 10, 21213-21223. doi:10. 1021/acsami.8b01749

Jo, H. J., Soo, C. Y., Dong, G., Do, Y. S., Wang, H. H., Lee, M. J., et al. (2015). Thermally rearranged poly(benzoxazole-co-imide) membranes with superior mechanical strength for gas separation obtained by tuning chain rigidity. Macromolecules 48, 2194-2202. doi:10.1021/acs.macromol.5b00413

Jones, C. W. (2011). $\mathrm{CO}_{2}$ capture from dilute gases as a component of modern global carbon management. Annu. Rev. Chem. 2, 31-52. doi:10.1146/annurevchembioeng-061010-114252

Jou, F. Y., Mather, A. E., and Otto, F. D. (1995). The solubility of $\mathrm{CO}_{2}$ in a 30 mass percent monoethanolamine solution. Can. J. Chem. Eng. 73, 140-147. doi:10. $1002 /$ cjce. 5450730116

Julian, H., Sutrisna, P. D., Hakim, A. N., Harsono, H. O., Hugo, Y. A., and Wenten, I. G. (2019). Nano-silica/polysulfone asymmetric mixed-matrix membranes (MMMs) with high $\mathrm{CO}_{2}$ permeance in the application of $\mathrm{CO}_{2} / \mathrm{N}_{2}$ separation. Polym.-Plast. Technol. 58, 678-689. doi:10.1080/03602559.2018.1520253

Jurado, N., Darabkhani, H. G., Anthony, E. J., and Oakey, J. E. (2015). "Oxy-fuel combustion for carbon capture and sequestration (CCS) from a coal/biomass power plant: experimental and simulation studies," in Progress in clean energy, volume 2: novel systems and applications. Editors I. Dincer, C.O. Colpan,
O. Kizilkan, and M.A. Ezan (Cham, Switzerland: Springer International Publishing), Vol. 2, 177-192

Kar, S., Goeppert, A., and Prakash, G. K. S. (2019). Integrated $\mathrm{CO}_{2}$ capture and conversion to formate and methanol: connecting two threads. Accounts Chem. Res. 52, 2892-2903. doi:10.1021/acs.accounts.9b00324

Kather, A., Rafailidis, S., Hermsdorf, C., Klostermann, M., Maschmann, A., Mieske, K., et al. (2008). Research and development needs for clean coal deployment. London, UK: International Energy Association Clean Coal Centre

Keith, D. W. (2009). Why capture $\mathrm{CO}_{2}$ from the atmosphere? Science 325 , 1654-1655. doi:10.1126/science.1175680

Khan, A. A., Halder, G. N., and Saha, A. K. (2016). Experimental investigation of sorption characteristics of capturing carbon dioxide into piperazine activated aqueous 2-amino-2-methyl-1-propanol solution in a packed column. Int. J. Greenh. Gas Control 44, 217-226. doi:10.1016/j.ijggc.2015.11.020

Kiehl, J. (2011). Lessons from earth's past. Science 331, 158-159. doi:10.1126/ science. 1199380

Kilaru, P. K. and Scovazzo, P. (2008). Correlations of low-pressure carbon dioxide and hydrocarbon solubilities in imidazolium-, phosphonium-, and ammonium-based room-temperature ionic liquids. Part 2. Using activation energy of viscosity. Ind. Eng. Chem. 47, 910-919. doi:10.1021/ie070836b

Kim, J., Lin, L.-C., Swisher, J. A., Haranczyk, M., and Smit, B. (2012). Predicting large $\mathrm{CO}_{2}$ adsorption in aluminosilicate zeolites for postcombustion carbon dioxide capture. J. Am. Chem. Soc. 134, 18940-18943. doi:10.1021/ja309818u

Kim, C., Cho, H. S., Chang, S., Cho, S. J., and Choi, M. (2016). An ethylenediaminegrafted $\mathrm{Y}$ zeolite: a highly regenerable carbon dioxide adsorbent via temperature swing adsorption without urea formation. Energy Environ. Sci. 9, 1803-1811. doi:10.1039/C6EE00601A

Kim, S. M., Abdala, P. M., Broda, M., Hosseini, D., Copéret, C., and Müller, C. (2018). Integrated $\mathrm{CO}_{2}$ capture and conversion as an efficient process for fuels from greenhouse gases. ACS Catalysis 8, 2815-2823. doi:10.1021/acscatal. $7 \mathrm{~b} 03063$

Kim, C., Choi, W., and Choi, M. (2019). $\mathrm{SO}_{2}$-Resistant amine-containing $\mathrm{CO}_{2}$ adsorbent with a surface protection layer. ACS Appl. Mater. Interfaces 11, 16586-16593. doi:10.1021/acsami.9b02831

Koros, W. J. (2004). Evolving beyond the thermal age of separation processes: membranes can lead the way. AIChE J. 50, 2326-2334. doi:10.1002/aic.10330

Kulkarni, A. R. and Sholl, D. S. (2012). Analysis of equilibrium-based TSA processes for direct capture of $\mathrm{CO}_{2}$ from air. Ind. Eng. Chem. Res. 51, 8631-8645. doi:10.1021/ie300691c

Kumar, P. and Guliants, V. V. (2010). Periodic mesoporous organic-inorganic hybrid materials: applications in membrane separations and adsorption. Micropor. Mesopor. Mat. 132, 1-14. doi:10.1016/j.micromeso.2010.02.007

Lackner, K., Ziock, H.-J., and Grimes, P. (1999). "Carbon dioxide extraction from air: is it an option?," in 24th annual technical conference on coal utilization and fuel systems, Clearwater, FL, March 8, 1999-March 11, 1999

Lackner, K. S., Brennan, S., Matter, J. M., Park, A.-H. A., Wright, A., and van der Zwaan, B. (2012). The urgency of the development of $\mathrm{CO}_{2}$ capture from ambient air. Proc. Natl. Acad. Sci. Unit. States Am. 109, 13156-13162. doi:10. 1073/pnas.1108765109

Lackner, K. S. (2003). A guide to $\mathrm{CO}_{2}$ sequestration Science 300, 1677-1678. doi:10. $1126 /$ science. 1079033

Lee, W. R., Hwang, S. Y., Ryu, D. W., Lim, K. S., Han, S. S., Moon, D., et al. (2014). Diamine-functionalized metal-organic framework: exceptionally high $\mathrm{CO}_{2}$ capacities from ambient air and flue gas, ultrafast $\mathrm{CO}_{2}$ uptake rate, and adsorption mechanism. Energy Environ. Sci. 7, 744-751. doi:10.1039/ C3EE42328J

Lee, T. S., Cho, J. H., and Chi, S. H. (2015). Carbon dioxide removal using carbon monolith as electric swing adsorption to improve indoor air quality. Build. Environ. 92, 209-221. doi:10.1016/j.buildenv.2015.04.028

Lewis, W. K., Gilliland, E. R., and Sweeney, M. P. (1951). Gasification of carbon: metal oxides in a fluidized powder bed. Chem. Eng. Prog. 47, 251-256

Li, L. and Rochelle, G. (2014). $\mathrm{CO}_{2}$ mass transfer and solubility in aqueous primary and secondary amine. Energy Procedia 63, 1487-1496. doi:10.1016/j.egypro. 2014.11.158

Li, J., Lin, X., Ning, P. G., Cao, H. B., and Zhang, Y. (2014). Measurement and modelling of the solubility of carbon dioxide in aqueous 1,8-pmenthane-diamine solution. J. Chem. Thermodyn. 71, 64-70. doi:10. $1016 /$ j.jct.2013.11.018 
Li, X., Zhang, L., Luo, C., Zhang, Z., Xu, Y., and Zheng, C. (2018). Experimental investigation and process simulation of oxy-fuel flue gas denitrification in $\mathrm{CO}_{2}$ compression process. Energy Fuels 32, 11666-11673. doi:10.1021/acs. energyfuels. $8 \mathrm{~b} 02660$

Liang, Z., Fadhel, B., Schneider, C. J., and Chaffee, A. L. (2008). Stepwise growth of melamine-based dendrimers into mesopores and their $\mathrm{CO}_{2}$ adsorption properties. Micro. Meso. Mat. 111, 536-543. doi:10.1016/j.micromeso.2007. 08.030

Liao, J., Wang, Z., Gao, C., Li, S., Qiao, Z., Wang, M., et al. (2014). Fabrication of high-performance facilitated transport membranes for $\mathrm{CO}_{2}$ separation. Chemical Science 5, 2843-2849. doi:10.1039/C3SC53334D

Liguori, S. and Wilcox, J. (2018). "Design considerations for postcombustion $\mathrm{CO}_{2}$ capture with membranes," in Current trends and future developments on (bio-) membranes. Editors A. Basile and E.P. Favvas (Amsterdam, Netherlands: Elsevier), 385-413

Lin, L.-C., Berger, A. H., Martin, R. L., Kim, J., Swisher, J. A., Jariwala, K., et al. (2012). In silico screening of carbon-capture materials. Nature Materials 11, 633-641. doi:10.1038/nmat3336

Lin, Y. C., Kong, C. L., and Chen, L. (2016). Amine-functionalized metal-organic frameworks: structure, synthesis and applications. RSC $A d v .6,32598-32614$. doi:10.1039/C6RA01536K

Liu, Y. M., Shi, J. J., Chen, J., Ye, Q., Pan, H., Shao, Z. H., et al. (2010). Dynamic performance of $\mathrm{CO}_{2}$ adsorption with tetraethylenepentamine-loaded KIT-6. Micro. Meso. Mat. 134, 16-21. doi:10.1016/j.micromeso.2010. 05.002

Liu, A.-H., Ma, R., Song, C., Yang, Z.-Z., Yu, A., Cai, Y., et al. (2012). Equimolar $\mathrm{CO}_{2}$ capture by $\mathrm{N}$-substituted amino acid salts and subsequent conversion, Angew. Chem. Int. Ed. 51, 11306-11310. doi:10.1002/anie.201205362

Liu, L., Zhao, C., Xu, J., and Li, Y. (2015). Integrated $\mathrm{CO}_{2}$ capture and photocatalytic conversion by a hybrid adsorbent/photocatalyst material. Appl. Catal. B 179, 489-499. doi:10.1016/j.apcatb.2015.06.006

Liu, C., Greer, D. W., and O'Leary, B. W. (2016). "Advanced materials and membranes for gas separations: the UOP approach," in Nanotechnology: delivering on the promise. Washington, D.C.: American Chemical Society, Vol. 2, 119-135

Liu, Q., Paul, D. R., and Freeman, B. D. (2016). Gas permeation and mechanical properties of thermally rearranged (TR) copolyimides. Polymer 82, 378-391. doi:10.1016/j.polymer.2015.11.051

Long, J. R. and Yaghi, O. M. (2009). The pervasive chemistry of metal-organic frameworks. Chem. Soc. Rev. 38, 1213-1214. doi:10.1039/B903811F

Low, B. T., Zhao, L., Merkel, T. C., Weber, M., and Stolten, D. (2013). A parametric study of the impact of membrane materials and process operating conditions on carbon capture from humidified flue gas. J. Membr. Sci. 431, 139-155. doi:10. 1016/j.memsci.2012.12.014

Lu, W., Wei, Z., Gu, Z.-Y., Liu, T.-F., Park, J., Park, J., et al. (2014). Tuning the structure and function of metal-organic frameworks via linker design. Chem. Soc. Rev. 43, 5561-5593. doi:10.1039/C4CS00003]

Lyngfelt, A. and Mattisson, T. (2011). "Materials for chemical-looping combustion," in Efficient carbon capture for coal power plants. D. Stolten and V. Scherer (Weinheim, Germany: WILEY-VCH Verlag GmbH \& Co. $\mathrm{KGaA})$

Lyngfelt, A. (2014). Chemical-looping combustion of solid fuels - status of development. Appl. Energy 113, 1869-1873. doi:10.1016/j.apenergy.2013.05.043

Ma, X. L., Wang, X. X., and Song, C. S. (2009). "Molecular basket" sorbents for separation of $\mathrm{CO}_{2}$ and $\mathrm{H}_{2} \mathrm{~S}$ from various gas streams. J. Am. Chem. Soc. 131, 5777-5783. doi:10.1021/ja8074105

Mafra, L., Čendak, T., Schneider, S., Wiper, P. V., Pires, J., Gomes, J. R. B., et al. (2017). Structure of chemisorbed $\mathrm{CO}_{2}$ species in amine-functionalized mesoporous silicas studied by solid-state NMR and computer modeling. J. Am. Chem. Soc. 139, 389-408. doi:10.1021/jacs.6b11081

Maneeintr, K., Idem, R. O., Tontiwachwuthikul, P., and Wee, A. G. H. (2009). Synthesis, solubilities, and cyclic capacities of amino alcohols for $\mathrm{CO}_{2}$ capture from flue gas streams. Energy Procedia 1, 1327-1334. doi:10.1016/j.egypro. 2009.01.174

Markewitz, P., Kuckshinrichs, W., Leitner, W., Linssen, J., Zapp, P., Bongartz, R., et al. (2012). Worldwide innovations in the development of carbon capture technologies and the utilization of $\mathrm{CO}_{2}$. Energy Environ. Sci. 5, 7281-7305. doi:10.1039/C2EE03403D
Marocco Stuardi, F., MacPherson, F., and Leclaire, J. (2019). Integrated $\mathrm{CO}_{2}$ capture and utilization: a priority research direction. Curr. Opin. Green Sustain. Chem. 16, 71-76. doi:10.1016/j.cogsc.2019.02.003

Maroto-Valer, M. M., Song, C. S., and Soong, Y. (2002). Envrionmental challenges and greenhouse gas control for fossil fuel utilization in the 21st century. New York, NY: Kluwer Academic/Plenum Publishers

Martín, M. M. (2016). "Water," in Industrial chemical process analysis and design. Editors M.M. Martín (Boston, MA: Elsevier), Chap. 4, 125-197

McDonald, T. M., Mason, J. A., Kong, X., Bloch, E. D., Gygi, D., Dani, A., et al. (2015). Cooperative insertion of $\mathrm{CO}_{2}$ in diamine-appended metal-organic frameworks. Nature 519, 303-308. doi:10.1038/nature14327

Melillo, J. M., McGuire, A. D., Kicklighter, D. W., Moore, B., Vorosmarty, C. J., and Schloss, A. L. (1993). Global climate-change and terrestrial net primary production. Nature 363, 234-240. doi:10.1038/363234a0

Merkel, T. C., Lin, H., Wei, X., and Baker, R. (2010). Power plant post-combustion carbon dioxide capture: an opportunity for membranes. J. Membr. Sci. 359, 126-139. doi:10.1016/j.memsci.2009.10.041

Merkel, T. C., Wei, X., He, Z., White, L. S., Wijmans, J. G., and Baker, R. W. (2013). Selective exhaust gas recycle with membranes for $\mathrm{CO}_{2}$ capture from natural gas combined cycle power plants. Ind. Eng. Chem. Res. 52, 1150-1159. doi:10.1021/ ie $302110 \mathrm{z}$

Mesbah, M., Momeni, M., Soroush, E., Shahsavari, S., and Galledari, S. A. (2019). Theoretical study of $\mathrm{CO}_{2}$ separation from $\mathrm{CO}_{2} / \mathrm{CH}_{4}$ gaseous mixture using 2methylpiperazine -promoted potassium carbonate through hollow fiber membrane contactor. J. Environ. Chem. Eng. 7, 102781

Metz, B., Davidson, O., Coninck, H. d., Loos, M., and Meyer, L. (2005). IPCC special report on carbon dioxide capture and storage. Cambridge, UK: Cambridge University Press

Miguel, C. V., Soria, M. A., Mendes, A., and Madeira, L. M. (2017). A sorptive reactor for $\mathrm{CO}_{2}$ capture and conversion to renewable methane. Chem. Eng. J. 322, 590-602. doi:10.1016/j.cej.2017.04.024

Miller, B. G.,(2017). "Carbon dioxide emissions reduction and storage," in Clean coal engineering technology. 2nd Edn. Editors B.G. Miller (Oxford, UK: Butterworth-Heinemann), Chap. 13, 609-668

Min, K., Choi, W., Kim, C., and Choi, M. (2018a). Oxidation-stable aminecontaining adsorbents for carbon dioxide capture. Nat. Commun. 9, 726. doi:10.1038/s41467-018-03123-0

Min, K., Choi, W., Kim, C., and Choi, M. (2018b). Rational design of the polymeric amines in solid adsorbents for postcombustion carbon dioxide capture. ACS Appl. Mater. Interfaces 10, 23825-23833. doi:10.1021/acsami.8b05988

Mohamedali, M., Nath, D., Ibrahim, H., and Henni, A. (2016). Review of recent developments in $\mathrm{CO}_{2}$ capture using solid materials: metal organic frameworks (MOFs). London, UK: IntechOpen

Mondal, B. K., Bandyopadhyay, S. S., and Samanta, A. N. (2015). Vapor-liquid equilibrium measurement and ENRTL modeling of $\mathrm{CO}_{2}$ absorption in aqueous hexamethylenediamine. Fluid Phase Equil. 402, 102-112. doi:10.1016/j.fluid. 2015.05.033

Montagnaro, F., Silvestre-Albero, A., Silvestre-Albero, J., Rodríguez-Reinoso, F., Erto, A., Lancia, A., et al. (2015). Post-combustion $\mathrm{CO}_{2}$ adsorption on activated carbons with different textural properties. Micropor. Mesopor. Mat. 209, 157-164. doi:10.1016/j.micromeso.2014.09.037

Monteiro, J. G. M. S., Pinto, D. D. D., Zaidy, S. A. H., Hartono, A., and Svendsen, H. F. (2013). VLE data and modelling of aqueous N,N-diethylethanolamine (DEEA) solutions. Int. J. Greenh. Gas Control 19, 432-440. doi:10.1016/j. ijggc.2013.10.001

Mora Mendoza, E. Y., Sarmiento Santos, A., Vera López, E., Drozd, V., Durygin, A., Chen, J., et al. (2019). Iron oxides as efficient sorbents for $\mathrm{CO}_{2}$ capture. J. Mater. Res. 8, 2944-2956. doi:10.1016/j.jmrt.2019.05.002

Moya, C., Palomar, J., Gonzalez-Miquel, M., Bedia, J., and Rodriguez, F. (2014). Diffusion coefficients of $\mathrm{CO}_{2}$ in ionic liquids estimated by gravimetry. Ind. Eng. Chem. Res. 53, 13782-13789. doi:10.1021/ie501925d

Mutch, G. A., Shulda, S., McCue, A. J., Menart, M. J., Ciobanu, C. V., Ngo, C., et al. (2018). Carbon capture by metal oxides: unleashing the potential of the (111) facet. J. Am. Chem. Soc. 140, 4736-4742. doi:10.1021/jacs.8b01845

Nakagawa, K. (1998). A novel method of $\mathrm{CO}_{2}$ capture from high temperature gases. J. Electro.Society 145, 1344

Nakhjiri, A. T. and Heydarinasab, A. (2019). Computational simulation and theoretical modeling of $\mathrm{CO}_{2}$ separation using EDA, PZEA and PS 
absorbents inside the hollow fiber membrane contactor. J. Ind. Eng. Chem. 78, 106-115. doi:10.1016/j.jiec.2019.06.031

National Academies of Sciences, Engineering, and Medicine (2019). Negative emissions technologies and reliable sequestration: a research agenda. Washington, DC: The National Academies Press

Nguyen, D., Murialdo, M., Hornbostel, K., Pang, S., Ye, C., Smith, W., et al. (2019). $3 \mathrm{D}$ printed polymer composites for $\mathrm{CO}_{2}$ capture. Ind. Eng. Chem. Res. 58, 22015-22020. doi:10.1021/acs.iecr.9b04375

Niranjana, K., Jerald Maria Antony, G., and Raja, S. (2019). A study on adsorption of gases in the thin film nanocomposites. Mater. Today: Proceed. 8, 79-84. doi:10.1016/j.matpr.2019.02.083

Nouacer, A., Belaribi, F. B., Mokbel, I., and Jose, J. (2014). Solubility of carbon dioxide gas in some $2.5 \mathrm{M}$ tertiary amine aqueous solutions. J. Mol. Liq. 190, 68-73. doi:10.1016/j.molliq.2013.10.026

Nugent, P., Belmabkhout, Y., Burd, S. D., Cairns, A. J., Luebke, R., Forrest, K., et al. (2013). Porous materials with optimal adsorption thermodynamics and kinetics for $\mathrm{CO}_{2}$ separation. Nature 495, 80-84. doi:10.1038/nature11893

OECD (2012). OECD environmental Outlook to 2050. Paris, France: OECD publishing

Öhrman, O., Hedlund, J., and Sterte, J. (2004). Synthesis and evaluation of ZSM-5 films on cordierite monoliths. Appl. Catal. A: Gen. 270, 193-199. doi:10.1016/j. apcata.2004.05.004

Olajire, A. A. (2017). Synthesis of bare and functionalized porous adsorbent materials for $\mathrm{CO}_{2}$ capture. Greenh. Gases 7, 399-459. doi:10.1002/ghg.1657

Pacala, S. and Socolow, R. (2004). Stabilization wedges: solving the climate problem for the next 50 Years with current technologies. Science 305, 968. doi:10.1126/ science. 1100103

Papadopoulos, A. I., Tzirakis, F., Tsivintzelis, I., and Seferlis, P. (2019). Phasechange solvents and processes for postcombustion $\mathrm{CO}_{2}$ capture: a detailed review. Ind. Eng. Chem. Res. 58, 5088-5111. doi:10.1021/acs. iecr. 8 b06279

Park, J. Y., Yoon, S. J., Lee, H., Yoon, J. H., Shim, J. G., Lee, J. K., et al. (2002). Solubility of carbon dioxide in aqueous solutions of 2-amino-2-ethyl-1,3propanediol. Fluid Phase Equil. 202, 359-366. doi:10.1016/S0378-3812(02) $00142-5$

Patterson, B. D., Mo, F., Borgschulte, A., Hillestad, M., Joos, F., Kristiansen, T., et al. (2019). Renewable $\mathrm{CO}_{2}$ recycling and synthetic fuel production in a marine environment. Proc. Natl. Acad. Sci. Unit. States Am. 116, 12212-12219. doi:10. 1073/pnas.1902335116

Petkovic, M., Seddon, K. R., Rebelo, L. P. N., and Silva Pereira, C. (2011). Ionic liquids: a pathway to environmental acceptability. Chem. Soc. Rev. 40, 1383-1403. doi:10.1039/C004968A

Plaza, M. G., Pevida, C., Arenillas, A., Rubiera, F., and Pis, J. J. (2007). $\mathrm{CO}_{2}$ capture by adsorption with nitrogen enriched carbons. Fuel 86, 2204-2212. doi:10.1016/ j.fuel.2007.06.001

Powell, C. E. and Qiao, G. G. (2006). Polymeric $\mathrm{CO}_{2} / \mathrm{N}_{2}$ gas separation membranes for the capture of carbon dioxide from power plant flue gases. J. Membr. Sci. 279, 1-49. doi:10.1016/j.memsci.2005.12.062

Puxty, G., Rowland, R., Allport, A., Yang, Q., Bown, M., Burns, R., et al. (2009). Carbon dioxide postcombustion capture: a novel screening study of the carbon dioxide absorption performance of 76 amines. Environ. Sci. Technol. 43, 6427-6433. doi:10.1021/es901376a

Qi, R. and Henson, M. A. (1998). Optimization-based design of spiral-wound membrane systems for $\mathrm{CO}_{2} / \mathrm{CH}_{4}$ separations. Sep. Purif. Technol. 13, 209-225. doi:10.1016/S1383-5866(98)00044-6

Qi, G., Wang, Y., Estevez, L., Duan, X., Anako, N., Park, A.-H. A., et al. (2011). High efficiency nanocomposite sorbents for $\mathrm{CO}_{2}$ capture based on aminefunctionalized mesoporous capsules. Energy Environ. Sci. 4, 444-452. doi:10. 1039/C0EE00213E

Rackley, S. A. (2017). "Carbon capture from power generation," in Carbon capture and storage. 2nd Edn. Editors S.A. Rackley (Boston, MA: ButterworthHeinemann), Chap. 4, 75-101

Ram Reddy, M. K., Xu, Z. P., Lu, G. Q., and Diniz da Costa, J. C. (2006). Layered double hydroxides for $\mathrm{CO}_{2}$ capture: structure evolution and regeneration. Ind. Eng. Chem. Res. 45, 7504-7509. doi:10.1021/ie060757k

Ram Reddy, M. K., Xu, Z. P., and Diniz da Costa, J. C. (2008). Influence of water on high-temperature $\mathrm{CO}_{2}$ capture using layered double hydroxide derivatives. Ind. Eng. Chem. Res. 47, 2630-2635. doi:10.1021/ie0716060
Ramasubramanian, K. and Ho, W. S. W. (2011). Recent developments on membranes for post-combustion carbon capture. Curr. Opin. Chem. Eng. 1, 47-54. doi:10.1016/j.coche.2011.08.002

Ramasubramanian, K., Verweij, H., and Winston Ho, W. S. (2012). Membrane processes for carbon capture from coal-fired power plant flue gas: a modeling and cost study. J. Membr. Sci. 421-422, 299-310. doi:10.1016/j.memsci.2012.07.029

Ramos-Fernandez, E. V., Garcia-Domingos, M., Juan-Alcañiz, J., Gascon, J., and Kapteijn, F. (2011). MOFs meet monoliths: hierarchical structuring metal organic framework catalysts. Appl. Cataly. A: General 391, 261-267. doi:10. 1016/j.apcata.2010.05.019

Razavi, S. S., Hashemianzadeh, S. M., and Karimi, H. (2011). Modeling the adsorptive selectivity of carbon nanotubes for effective separation of $\mathrm{CO}_{2} /$ $\mathrm{N}_{2}$ mixtures. J. Mol. Model. 17, 1163-1172. doi:10.1007/s00894-010-0810-9

Realmonte, G., Drouet, L., Gambhir, A., Glynn, J., Hawkes, A., Köberle, A. C., et al. (2019). An inter-model assessment of the role of direct air capture in deep mitigation pathways. Nat. Commun. 10, 3277. doi:10.1038/s41467-019-10842-5

Rebolledo-Morales, M. A., Rebolledo-Libreros, M. E., and Trejo, A. (2011). Equilibrium solubility of $\mathrm{CO}_{2}$ in aqueous solutions of 1-amino-2-propanol as function of concentration, temperature, and pressure. J. Chem. Thermodyn. 43, 690-695. doi:10.1016/j.jct.2010.12.008

Regufe, M. J., Ferreira, A. F. P., Loureiro, J. M., Rodrigues, A., and Ribeiro, A.- M. (2019). Electrical conductive 3D-printed monolith adsorbent for $\mathrm{CO}_{2}$ capture. Micropor. Mesopor. Mater. 278, 403-413. doi:10.1016/j.micromeso.2019.01.009

Rezaei, F. and Webley, P. (2009). Optimum structured adsorbents for gas separation processes. Chem. Eng. Sci. 64, 5182-5191. doi:10.1016/j.ces.2009. 08.029

Rezaei, F. and Webley, P. (2010). Structured adsorbents in gas separation processes. Sep. Purif. Technol. 70, 243-256. doi:10.1016/j.seppur.2009.10.004

Rochelle, G. T. (2009). Amine scrubbing for $\mathrm{CO}_{2}$ capture. Science 325, 1652-1654. doi:10.1126/science.1176731

Rochelle, G. T. (2016). "Conventional amine scrubbing for $\mathrm{CO}_{2}$ capture," in Absorption-based post-combustion capture of carbon dioxide. Editors P.H.M. Feron (Cambridge, UK: Woodhead Publishing), Chap. 3, 35-67

Rodríguez, M. T. and Pfeiffer, H. (2008). Sodium metasilicate $\left(\mathrm{Na}_{2} \mathrm{SiO}_{3}\right)$ : a thermokinetic analysis of its $\mathrm{CO}_{2}$ chemical sorption. Thermochimica Acta 473, 92-95. doi:10.1016/j.tca.2008.04.022

Rosenholm, J. M. and Linden, M. (2007). Wet-chemical analysis of surface concentration of accessible groups on different amino-functionalized mesoporous SBA-15 silicas. Chem. Mat. 19, 5023-5034. doi:10.1021/ $\mathrm{cm} 071289 \mathrm{n}$

Rosenholm, J. M., Penninkangas, A., and Linden, M. (2006). Aminofunctionalization of large-pore mesoscopically ordered silica by a one-step hyperbranching polymerization of a surface-grown polyethyleneimine. Chem. Commun. 37, 3909-3911. doi:10.1039/B607886A

Rubin, E. S., Davison, J. E., and Herzog, H. J. (2015). The cost of $\mathrm{CO}_{2}$ capture and storage. Int. J. Greenh. Gas Control. 40, 378-400. doi:10.1016/j.ijggc.2015.05. 018

Sanz-Pérez, E. S., Murdock, C. R., Didas, S. A., and Jones, C. W. (2016). Direct capture of $\mathrm{CO}_{2}$ from ambient air. Chem. Rev. 116, 11840-11876. doi:10.1021/ acs.chemrev.6b00173

Sarfraz, M. and Ba-Shammakh, M. (2018). ZIF-based water-stable mixed-matrix membranes for effective $\mathrm{CO}_{2}$ separation from humid flue gas. Can. J. Chem. Eng. 96, 2475-2483. doi:10.1002/cjce.23170

Schäffer, A., Brechtel, K., and Scheffknecht, G. (2012). Comparative study on differently concentrated aqueous solutions of MEA and TETA for $\mathrm{CO}_{2}$ capture from flue gases. Fuel 101, 148-153. doi:10.1016/j.fuel.2011.06.037

Scholes, C. A., Kentish, S. E., and Qader, A. (2020). Membrane gas-solvent contactor pilot plant trials for post-combustion $\mathrm{CO}_{2}$ capture. Sep. Purif. Technol. 237, 116470. doi:10.1016/j.seppur.2019.116470

Scholes, C. A. (2016). Thermally rearranged poly(benzoxazole) copolymer membranes for improved gas separation: a review. Aust. J. Chem. 69, 601-611. doi:10.1071/CH15523

Scholz, M., Frank, B., Stockmeier, F., Falß, S., and Wessling, M. (2013). Technoeconomic analysis of hybrid processes for biogas upgrading. Ind. Eng. Chem. Res. 52, 16929-16938. doi:10.1021/ie402660s

Seneviratne, S. I., Donat, M. G., Pitman, A. J., Knutti, R., and Wilby, R. L. (2016). Allowable $\mathrm{CO}_{2}$ emissions based on regional and impact-related climate targets. Nature 529, 477. doi:10.1038/nature16542 
Seo, D. J. and Hong, W. H. (2000). Effect of piperazine on the kinetics of carbon dioxide with aqueous solutions of 2-Amino-2-methyl-1-propanol. Ind. Eng. Chem. Res. 39, 2062-2067. doi:10.1021/ie990846f

Shah, K. J. and Imae, T. (2016). Selective gas capture ability of gas-adsorbentincorporated cellulose nanofiber films. Biomacromolecules 17, 1653-1661. doi:10.1021/acs.biomac.6b00065

Shannon, M. S. and Bara, J. E. (2012). Reactive and reversible ionic liquids for $\mathrm{CO}_{2}$ capture and acid gas removal. Sep. Sci. Technol. 47, 178-188. doi:10.1080/ 01496395.2011.630055

Shen, K. P. and Li, M. H. (1992). Solubility of carbon dioxide in aqueous mixtures of monoethanolamine with methyldiethanolamine. J. Chem. Eng. Data 37, 96-100. doi:10.1021/je00005a025

Shiflett, M. B. and Yokozeki, A. (2005). Solubilities and diffusivities of carbon dioxide in ionic liquids: [bmim][PF6] and [bmim][BF4]. Ind. Eng. Chem. 44, 4453-4464. doi:10.1021/ie058003d

Shiflett, M. B., Drew, D. W., Cantini, R. A., and Yokozeki, A. (2010). Carbon dioxide capture using ionic liquid 1-Butyl-3-methylimidazolium acetate. Energy Fuels 24, 5781-5789. doi:10.1021/ef100868a

Shimon, D., Chen, C.-H., Lee, J. J., Didas, S. A., Sievers, C., Jones, C. W., et al. (2018). ${ }^{15} \mathrm{~N}$ solid state NMR spectroscopic study of surface amine groups for carbon capture: 3-aminopropylsilyl grafted to SBA-15 mesoporous silica. Environ Sci Technol 52, 1488-1495. doi:10.1021/acs.est.7b04555

Shin, E. K., Lee, B. C., and Lim, J. S. (2008). High-pressure solubilities of carbon dioxide in ionic liquids: 1-Alkyl-3-methylimidazolium bis(trifluoromethylsulfonyl)imide. J. Supercrit. Fluids 45, 282-292. doi:10.1016/j.supflu.2008.01.020

Siagian, U. W. R., Raksajati, A., Himma, N. F., Khoiruddin, K., and Wenten, I. G. (2019). Membrane-based carbon capture technologies: membrane gas separation vs. membrane contactor. J Nat Gas Sci Eng. 67, 172-195. doi:10. 1016/j.jngse.2019.04.008

Singh, J. and Dhar, D. W. (2019). Overview of carbon capture technology: microalgal biorefinery concept and state-of-the-art. Front. Mar. Sci. 6, 1-9. doi:10.3389/fmars.2019.00029

Singh, G., Lee, J., Karakoti, A., Bahadur, R., Yi, J., Zhao, D., et al. (2020). Emerging trends in porous materials for $\mathrm{CO}_{2}$ capture and conversion. Chem. Soc. Rev. 49, 4360-4404. doi:10.1039/D0CS00075B

Siriwardane, R. V., Shen, M. S., and Fisher, E. P. (2003). Adsorption of $\mathrm{CO}_{2}, \mathrm{~N}_{2}$, and $\mathrm{O}_{2}$ on natural zeolites. Energy Fuels 17, 571-576. doi:10.1021/ef0201351

Smith, M. R. and Myers, S. S. (2018). Impact of anthropogenic $\mathrm{CO}_{2}$ emissions on global human nutrition. Nat. Clim. Change 8, 834-839. doi:10.1038/s41558018-0253-3

Son, W. J., Choi, J. S., and Ahn, W. S. (2008). Adsorptive removal of carbon dioxide using polyethyleneimine-loaded mesoporous silica materials. Micropor. Mesopor. Mater. 113, 31-40. doi:10.1016/j.micromeso.2007.10.049

Song, C., Liu, Q., Ji, N., Deng, S., Zhao, J., Li, Y., et al. (2018). Alternative pathways for efficient $\mathrm{CO}_{2}$ capture by hybrid processes-a review. Renew. Sustain. Energy Rev. 82, 215-231. doi:10.1016/j.rser.2017.09.040

Song, C. S. (2006). Global challenges and strategies for control, conversion and utilization of $\mathrm{CO}_{2}$ for sustainable development involving energy, catalysis, adsorption and chemical processing. Catal. Today 115, 2-32. doi:10.1016/j. cattod.2006.02.029

Songolzadeh, M., Soleimani, M., Ravanchi, M. T., and Songolzadeh, R. (2014). Carbon dioxide separation from flue gases: a technological review emphasizing reduction in greenhouse gas emissions. Sci. World J. 2014, 828131. doi:10.1155/2014/828131

Sreedhar, I., Nahar, T., Venugopal, A., and Srinivas, B. (2017). Carbon capture by absorption - path covered and ahead. Renew. Sustain. Energy Rev. 76, 1080-1107. doi:10.1016/j.rser.2017.03.109

Steinberg, M. and Cheng, H. C. (1989). Modern and prospective technologies for hydrogen production from fossil fuels. Int. J. Hydrog. 14, 797-820. doi:10.1016/ 0360-3199(89)90018-9

Stocker, T. F., Qin, D., Plattner, G.-K., Tignor, M., Allen, S. K., Boschung, J., et al. (2013). Climate change 2013: the physical science basis. Contribution of working group I to the fifth assessment report of the intergovernmental Panel on climate change. Cambridge, UK and New York, NY: Cambridge University Press, 1585

Taheri Najafabadi, A. (2015). Emerging applications of graphene and its derivatives in carbon capture and conversion: current status and future prospects. Renew. Sustain. Energy Rev. 41, 1515-1545. doi:10.1016/j.rser.2014.09.022
Takamura, Y., Narita, S., Aoki, J., Hironaka, S., and Uchida, S. (2001). Evaluation of dual-bed pressure swing adsorption for $\mathrm{CO}_{2}$ recovery from boiler exhaust gas. Sep. Purif. Technol. 24, 519-528. doi:10.1016/S1383-5866(01)00151-4

Tanh Jeazet, H. B., Staudt, C., and Janiak, C. (2012). Metal-organic frameworks in mixed-matrix membranes for gas separation. Dalton Trans. 41, 14003-14027. doi:10.1039/C2DT31550E

Tanthana, J. and Chuang, S. S. C. (2010). In Situ infrared study of the role of PEG in stabilizing silica-supported amines for $\mathrm{CO}_{2}$ capture. Chemsuschem 3, 957-964. doi:10.1002/cssc.201000090

Thakkar, H., Eastman, S., Hajari, A., Rownaghi, A. A., Knox, J. C., and Rezaei, F. (2016). 3D-Printed zeolite monoliths for $\mathrm{CO}_{2}$ removal from enclosed environments. ACS Appl. Mater. Interfaces 8, 27753-27761. doi:10.1021/acsami.6b09647

Thakkar, H., Eastman, S, Al-Mamoori, A., Hajari, A., Rownaghi, A. A., and Rezaei, F. (2017a). Formulation of aminosilica adsorbents into 3D-printed monoliths and evaluation of their $\mathrm{CO}_{2}$ capture performance. ACS Appl. Mater. Interfaces 9, 7489-7498. doi:10.1021/acsami.6b16732

Thakkar, H., Eastman, S., Al-Naddaf, Q., Rownaghi, A. A., and Rezaei, F. (2017b). 3D-Printed metal-organic framework monoliths for gas adsorption processes. ACS Appl. Mater. Interfaces 9, 35908-35916. doi:10.1021/acsami.7b11626

Thakkar, H., Lawson, S., Rownaghi, A. A., and Rezaei, F. (2018). Development of 3D-printed polymer-zeolite composite monoliths for gas separation. Chem. Eng. J. 348, 109-116. doi:10.1016/j.cej.2018.04.178

Thompson, J. F., Bellerjeau, C., Marinick, G., Osio-Norgaard, J., Evans, A., Carry, P., et al. (2019). Intrinsic thermal desorption in a 3D printed multifunctional composite $\mathrm{CO}_{2}$ sorbent with embedded heating capability. ACS Appl. Mater. Interfaces 11, 43337-43343. doi:10.1021/acsami.9b14111

Tim Cullinane, J., Oyenekan, B. A., Lu, J., and Rochelle, G. T. (2005). "Aqueous piperazine/potassium carbonate for enhanced $\mathrm{CO}_{2}$ capture," in Greenhouse gas control technologies 7. Editors E.S. Rubin, D.W. Keith, C.F. Gilboy, M. Wilson, T. Morris, J. Gale, et al. (Oxford, UK: Elsevier Science Ltd)

Tong, D., Trusler, J. P. M., Maitland, G. C., Gibbins, J., and Fennell, P. S. (2012). Solubility of carbon dioxide in aqueous solution of monoethanolamine or 2amino-2-methyl-1-propanol: experimental measurements and modelling. Int. J. Greenh. Gas Control 6, 37-47. doi:10.1016/j.ijggc.2011.11.005

Tontiwachwuthikul, P. and Idem, R. (2013). "Recent progress and new developments in post-combustion carbon-capture technology with reactive solvents," in Recent progress and new developments in post-combustion carboncapture technology with reactive solvents, Editors P. Tontiwachwuthikul and R. Idem, Future Science Book Series, pp. 2-8.

Torrisi, A., Bell, R. G., and Mellot-Draznieks, C. (2010). Functionalized MOFs for enhanced $\mathrm{CO}_{2}$ capture. Cryst. Growth Des. 10, 2839-2841. doi:10.1021/cg100646e

Tsuda, T. and Fujiwara, T. (1992). Polyethyleneimine and macrocyclic polyamine silica gels acting as carbon dioxide absorbents. J. Chem. Soc.-Chem. Commun. 1659-1661. doi:10.1039/C39920001659

Tsuda, T., Fujiwara, T., Taketani, Y., and Saegusa, T. (1992). Amino silica gels acting as a carbon dioxide absorbent. Chem. Lett. 21, 2161-2164. doi:10.1246/cl.1992.2161

United Nations Climate Change (2015). The Paris agreement. Available at: https:// unfccc.int/process-and-meetings/the-paris-agreement/the-paris-agreement. (Accessed October 15, 2019).

United States Environmental Protection Agency (2016). Inventory of U.S. Greenhouse gas emissions and sinks: 1990-2014. Washington DC: US EPA, 558. Available at: https://www.epa.gov/sites/production/files/2017-04/documents/us-ghg-inventory2016-main-text.pdf (Accessed April 15, 2016).

U.S. Energy Information Administration (2020). DOE/EIA-0035(2020/6). Monthly energy review, June 2020. Available at: https://www.eia.gov/ totalenergy/data/monthly/archive/00352006.pdf

Vaccarelli, M., Carapellucci, R., and Giordano, L. (2014). Energy and economic analysis of the $\mathrm{CO}_{2}$ capture from flue gas of combined cycle power plants. Energy Procedia 45, 1165-1174. doi:10.1016/j.egypro.2014.01.122

Vinoba, M., Bhagiyalakshmi, M., Alqaheem, Y., Alomair, A. A., Pérez, A., and Rana, M. S. (2017). Recent progress of fillers in mixed matrix membranes for $\mathrm{CO}_{2}$ separation: a review. Sep. Purif. Technol. 188, 431-450. doi:10.1016/j.seppur.2017.07.051

Vitillo, J. G., Smit, B., and Gagliardi, L. (2017). Introduction: carbon capture and separation. Chem. Rev. 117, 9521-9523. doi:10.1021/acs.chemrev.7b00403

Wang, X. and Song, C. (2019). "Capture of $\mathrm{CO}_{2}$ from concentrated sources and the atmosphere," in An economy based on carbon dioxide and water: potential of large scale carbon dioxide utilization. Editors M. Aresta, I. Karimi, and S. Kawi (Switzerland, Cham: Springer International Publishing), 35-72 
Wang, Y. M., Wu, Z. Y., Shi, L. Y., and Zhu, J. H. (2005). Rapid functionalization of mesoporous materials: directly dispersing metal oxides into as-prepared SBA15 occluded with template. Adv. Mater. 17, 323-327. doi:10.1002/adma. 200400860

Wang, X. X., Schwartz, V., Clark, J. C., Ma, X. L., Overbury, S. H., Xu, X. C., et al. (2009). Infrared study of $\mathrm{CO}_{2}$ sorption over "molecular basket" sorbent consisting of polyethylenimine-modified mesoporous molecular sieve. J. Phys. Chem. C 113, 7260-7268. doi:10.1021/jp809946y

Wang, C., Luo, X., Luo, H., Jiang, D.-e., Li, H., and Dai, S. (2011). Tuning the basicity of ionic liquids for equimolar $\mathrm{CO}_{2}$ capture. Angew. Chem. Int. Ed. Engl. 50, 4918-4922. doi:10.1002/anie.201008151

Wang, D. X., Sentorun-Shalaby, C., Ma, X. L., and Song, C. S. (2011). High-capacity and low-cost carbon-based "molecular basket" sorbent for $\mathrm{CO}_{2}$ capture from flue gas. Energy Fuels 25, 456-458. doi:10.1021/ef101364c

Wang, Q., Luo, J., Zhong, Z., and Borgna, A. (2011). $\mathrm{CO}_{2}$ capture by solid adsorbents and their applications: current status and new trends. Energy Environ. Sci. 4, 42-55. doi:10.1039/C0EE00064G

Wang, C., Liu, X., Keser Demir, N., Chen, J. P., and Li, K. (2016). Applications of water stable metal-organic frameworks. Chem. Soc. Rev. 45, 5107-5134. doi:10. 1039/C6CS00362A

Wang, S., Li, X., Wu, H., Tian, Z., Xin, Q., He, G., et al. (2016). Advances in high permeability polymer-based membrane materials for $\mathrm{CO}_{2}$ separations. Energy Environ. Sci. 9, 1863-1890. doi:10.1039/C6EE00811A

Wang, S., Schrunk, E. T., Mahajan, H., and Farrauto, A. R. J. (2017). The role of ruthenium in $\mathrm{CO}_{2}$ capture and catalytic conversion to fuel by dual function materials (DFM). Catalysts 7, 88

Wang, Y., Zhao, L., Otto, A., Robinius, M., and Stolten, D. (2017). A review of postcombustion $\mathrm{CO}_{2}$ capture technologies from coal-fired power plants. Energy Procedia 114, 650-665. doi:10.1016/j.egypro.2017.03.1209

Wang, S., Farrauto, R. J., Karp, S., Jeon, J. H., and Schrunk, E. T. (2018). Parametric, cyclic aging and characterization studies for $\mathrm{CO}_{2}$ capture from flue gas and catalytic conversion to synthetic natural gas using a dual functional material (DFM). J. CO2 Util. 27, 390-397. doi:10.1016/j.jcou. 2018.08.012

Wang, X., Fujii, M., Wang, X., and Song, C. (2020). New approach to enhance $\mathrm{CO}_{2}$ capture of "molecular basket" sorbent by using 3-aminopropyltriethoxysilane to reshape fumed silica support. Ind. Eng. Chem. Res. 59, 7267-7273. doi:10. 1021/acs.iecr.9b06459

Wappel, D., Gronald, G., Kalb, R., and Draxler, J. (2010). Ionic liquids for postcombustion $\mathrm{CO}_{2}$ absorption. Int. J. Greenh. Gas Control 4, 486-494. doi:10. 1016/j.ijggc.2009.11.012

Webley, P. A. (2014). Adsorption technology for $\mathrm{CO}_{2}$ separation and capture: a perspective. Adsorption 20, 225-231. doi:10.1007/s10450-014-9603-2

Wu, H., Li, X., Li, Y., Wang, S., Guo, R., Jiang, Z., et al. (2014). Facilitated transport mixed matrix membranes incorporated with amine functionalized MCM-41 for enhanced gas separation properties. J. Membr. Sci. 465, 78-90. doi:10.1016/j. memsci.2014.04.023

Wu, H., Chen, W., Wu, J., Zheng, Z., and Duan, L. (2019). Synergistic removal of SOx and $\mathrm{NOx}$ in $\mathrm{CO}_{2}$ compression and purification in oxy-fuel combustion power plant. Energy Fuels 33, 12621-12627. doi:10.1021/acs.energyfuels. $9 \mathrm{~b} 03284$

Xu, X. C., Song, C. S., Andresen, J. M., Miller, B. G., and Scaroni, A. W. (2002). Novel polyethylenimine-modified mesoporous molecular sieve of MCM-41 type as high-capacity adsorbent for $\mathrm{CO}_{2}$ capture. Energy Fuels 16, 1463-1469. doi:10.1021/ef020058u

Xu, X. C., Song, C. S., Andresen, J. M., Miller, B. G., and Scaroni, A. W. (2003). Preparation and characterization of novel $\mathrm{CO}_{2}$ "molecular basket" adsorbents based on polymer-modified mesoporous molecular sieve MCM-41. Micropor. Mesopor. Mater. 62, 29-45. doi:10.1016/S13871811(03)00388-3

Xu, X. C., Song, C. S., Miller, B. G., and Scaroni, A. W. (2005). Influence of moisture on $\mathrm{CO}_{2}$ separation from gas mixture by a nanoporous adsorbent based on polyethylenimine-modified molecular sieve MCM-41. Ind. Eng. Chem. Res. 44, 8113-8119. doi:10.1021/ie050382n

Xu, D., Xiao, P., Zhang, J., Li, G., Xiao, G., Webley, P. A., et al. (2013). Effects of water vapour on $\mathrm{CO}_{2}$ capture with vacuum swing adsorption using activated carbon. Chem. Eng. J. 230, 64-72. doi:10.1016/j.cej.2013.06.080
Xu, X., Pejcic, B., Heath, C., and Wood, C. D. (2018). Carbon capture with polyethylenimine hydrogel beads (PEI HBs). J. Mater. Chem. A 6, 21468-21474. doi:10.1039/C8TA07760F

Yamada, H., Chowdhury, F. A., Goto, K., and Higashii, T. (2013). $\mathrm{CO}_{2}$ solubility and species distribution in aqueous solutions of 2-(isopropylamino)ethanol and its structural isomers. Int. J. Greenh. Gas Control. 17, 99-105. doi:10.1016/j. ijggc.2013.03.027

Yan, Y., Mattisson, T., Moldenhauer, P., Anthony, E. J., and Clough, P. T. (2020). Applying machine learning algorithms in estimating the performance of heterogeneous, multi-component materials as oxygen carriers for chemicallooping processes. Chem. Eng. Trans. 387, 124072. doi:10.1016/j.cej.2020.124072

Yang, Z.-Z., He, L.-N., Zhao, Y.-N., Li, B., and Yu, B. (2011a). $\mathrm{CO}_{2}$ capture and activation by superbase/polyethylene glycol and its subsequent conversion. Energy Environ. Sci. 4, 3971-3975. doi:10.1039/C1EE02156G

Yang, Z.-Z., Zhao, Y.-N., and He, L.-N. (2011b). $\mathrm{CO}_{2}$ chemistry: task-specific ionic liquids for $\mathrm{CO}_{2}$ capture/activation and subsequent conversion. RSC Adv. 1, 545-567. doi:10.1039/C1RA00307K

Yang, S. B., Zhan, L., Xu, X. Y., Wang, Y. L., Ling, L. C., and Feng, X. L. (2013). Graphene-based porous silica sheets impregnated with polyethyleneimine for superior $\mathrm{CO}_{2}$ capture. Adv. Mater. 25, 2130-2134. doi:10.1002/adma.201204427

Yong, Z., Mata, V., and Rodriguez, A. E. (2001). Adsorption of carbon dioxide onto hydrotalcite-like compounds (HTlcs) at high temperatures. Ind. Eng. Chem. Res. 40, 204-209. doi:10.1021/ie000238w

Yong, W. F., Lee, Z. K., Chung, T.-S., Weber, M., Staudt, C., and Maletzko, C. (2016). Blends of a polymer of intrinsic microporosity and partially sulfonated polyphenylenesulfone for gas separation. ChemSusChem 9, 1953-1962. doi:10. $1002 /$ cssc. 201600354

Yong, J. K. J. (2016). The development of thin films for efficient carbon capture and storage. PhD thesis. (Melbourne, Australia: The University of Melbourne)

Yoshimune, M. and Haraya, K. (2013). $\mathrm{CO}_{2} / \mathrm{CH}_{4}$ mixed gas separation using carbon hollow fiber membranes. Energy Procedia 37, 1109-1116. doi:10.1016/j. egypro.2013.05.208

Yu, C. H., Huang, C. H., and Tan, C. S. (2012). A review of $\mathrm{CO}_{2}$ capture by absorption and adsorption. Aerosol Air Qual. Res. 12, 745-769. doi:10.4209/ aaqr.2012.05.0132

Yue, M. B., Chun, Y., Cao, Y., Dong, X., and Zhu, J. H. (2006). $\mathrm{CO}_{2}$ capture by Asprepared SBA-15 with an occluded organic template. Adv. Funct. Mater. 16, 1717-1722. doi:10.1002/adfm.200600427

Yue, M. B., Sun, L. B., Cao, Y., Wang, Y., Wang, Z. J., and Zhu, J. H. (2008). Efficient $\mathrm{CO}_{2}$ capturer derived from as-synthesized MCM-41 modified with amine. Chem. - A Eur. J. 14, 3442-3451. doi:10.1002/chem.200701467

Zelenak, V., Badanicova, M., Halamova, D., Cejka, J., Zukal, A., Murafa, N., et al. (2008a). Amine-modified ordered mesoporous silica: effect of pore size on carbon dioxide capture. Chem. Eng. J. 144, 336-342. doi:10.1016/j.cej.2008.07. 025

Zelenak, V., Halamova, D., Gaberova, L., Bloch, E., and Llewellyn, P. (2008b). Amine-modified SBA-12 mesoporous silica for carbon dioxide capture: effect of amine basicity on sorption properties. Micropor. Mesopor. Mater. 116, 358-364. doi:10.1016/j.micromeso.2008.04.023

Zeng, S., Zhang, X., Bai, L., Zhang, X., Wang, H., Wang, J., et al. (2017). Ionicliquid-based $\mathrm{CO}_{2}$ capture systems: structure, interaction and process. Chem. Rev. 117, 9625-9673. doi:10.1021/acs.chemrev.7b00072

Zhang, X., Liu, Z., and Wang, W. (2008). Screening of ionic liquids to capture $\mathrm{CO}_{2}$ by COSMO-RS and experiments. AIChE J. 54, 2717-2728. doi:10.1002/aic. 11573

Zhang, Z. H., Ma, X. L., Wang, D. X., Song, C. S., and Wang, Y. G. (2012). Development of silica-gel-supported polyethylenimine sorbents for $\mathrm{CO}_{2}$ capture from flue gas. Aiche J. 58, 2495-2502. doi:10.1002/aic.12771

Zhang, Y., Sunarso, J., Liu, S., and Wang, R. (2013). Current status and development of membranes for $\mathrm{CO}_{2} / \mathrm{CH}_{4}$ separation: a review. Int. J. Greenh. Gas Control 12, 84-107. doi:10.1016/j.ijggc.2012.10.009

Zhang, Z. J., Zhao, Y. G., Gong, Q. H., Li, Z., and Li, J. (2013). ChemInform Abstract:MOFs for $\mathrm{CO}_{2}$ capture and separation from flue gas mixtures: the effect of multifunctional sites on their adsorption capacity and selectivity. Chem. Commun. 49, 653-661. doi:10.1039/c2cc35561b

Zhang, R., Wang, X., Liu, S., He, L., Song, C., Jiang, X., et al. (2019). Discovering inherent characteristics of polyethylenimine-functionalized porous materials 
for $\mathrm{CO}_{2}$ capture. ACS Appl. Mater. Interfaces 11, 36515-36524. doi:10.1021/ acsami.9b08496

Zhou, H.-C., Long, J. R., and Yaghi, O. M. (2012). Introduction to metal-organic frameworks. Chem. Rev. 112, 673-674. doi:10.1021/cr300014x

Zhou, Z., Sun, N., Wang, B., Han, Z., Cao, S., Hu, D., et al. (2020). 2D-Layered $\mathrm{Ni}-\mathrm{MgO}-\mathrm{Al}_{2} \mathrm{O}_{3}$ nano-sheets for integrated capture and methanation of $\mathrm{CO}_{2}$. ChemSusChem 13, 360-368. doi:10.1002/cssc.201902828

Zhuang, Q., Clements, B., Dai, J., and Carrigan, L. (2016). Ten years of research on phase separation absorbents for carbon capture: achievements and next steps. Int. J. Greenh. Gas Control 52, 449-460. doi:10.1016/j.ijggc.2016.04.022
Conflict of Interest: The authors declare that the research was conducted in the absence of any commercial or financial relationships that could be construed as a potential conflict of interest.

Copyright $\odot 2020$ Wang and Song. This is an open-access article distributed under the terms of the Creative Commons Attribution License (CC BY). The use, distribution or reproduction in other forums is permitted, provided the original author(s) and the copyright owner(s) are credited and that the original publication in this journal is cited, in accordance with accepted academic practice. No use, distribution or reproduction is permitted which does not comply with these terms. 